\title{
Article \\ Performance and Deployment of Low-Cost Particle Sensor Units to Monitor Biomass Burning Events and Their Application in an Educational Initiative
}

\author{
Fabienne Reisen ${ }^{1, * \mathbb{D}}$, Jacinta Cooper ${ }^{1}$, Jennifer C. Powell ${ }^{1}$, Christopher Roulston ${ }^{1}$ and Amanda J. Wheeler ${ }^{2,3} \mathbb{D}$ \\ 1 CSIRO Oceans \& Atmosphere, Private Bag 1, Aspendale, VIC 3195, Australia; \\ jacintacooper29@gmail.com (J.C.); jennifer.powell@csiro.au (J.C.P.); Chris.roulston@csiro.au (C.R.) \\ 2 Mary MacKillop Institute for Health Research, Australian Catholic University, Melbourne, VIC 3000, \\ Australia; Amanda.Wheeler@acu.edu.au \\ 3 Menzies Institute for Medical Research, University of Tasmania, Hobart, TAS 7000, Australia \\ * Correspondence: Fabienne.reisen@csiro.au
}

Citation: Reisen, F.; Cooper, J.; Powell, J.C.; Roulston, C.; Wheeler, A.J. Performance and Deployment of Low-Cost Particle Sensor Units to Monitor Biomass Burning Events and Their Application in an Educational Initiative. Sensors 2021, 21, 7206. https://doi.org/10.3390/s21217206

Academic Editor: Ki-Hyun Kim

Received: 7 October 2021

Accepted: 26 October 2021

Published: 29 October 2021

Publisher's Note: MDPI stays neutral with regard to jurisdictional claims in published maps and institutional affiliations.

Copyright: (C) 2021 by the authors. Licensee MDPI, Basel, Switzerland. This article is an open access article distributed under the terms and conditions of the Creative Commons Attribution (CC BY) license (https:/ / creativecommons.org/licenses/by/ $4.0 /)$.

\begin{abstract}
Biomass burning smoke is often a significant source of airborne fine particles in regional areas where air quality monitoring is scarce. Emerging sensor technology provides opportunities to monitor air quality on a much larger geographical scale with much finer spatial resolution. It can also engage communities in the conversation around local pollution sources. The SMoke Observation Gadget (SMOG), a unit with a Plantower dust sensor PMS3003, was designed as part of a school-based Science, Technology, Engineering and Mathematics (STEM) project looking at smoke impacts in regional areas of Victoria, Australia. A smoke-specific calibration curve between the SMOG units and a standard regulatory instrument was developed using an hourly data set collected during a peat fire. The calibration curve was applied to the SMOG units during all field-based validation measurements at several locations and during different seasons. The results showed strong associations between individual SMOG units for $\mathrm{PM}_{2.5}$ concentrations $\left(\mathrm{r}^{2}=0.93-0.99\right)$ and good accuracy (mean absolute error $(\mathrm{MAE})<2 \mu \mathrm{g} \mathrm{m}^{-3}$ ). Correlations of the SMOG units to reference instruments also demonstrated strong associations $\left(\mathrm{r}^{2}=0.87-95\right)$ and good accuracy (MAE of 2.5-3.0 $\mu \mathrm{g} \mathrm{m}^{-3}$ ). The $\mathrm{PM}_{2.5}$ concentrations tracked by the SMOG units had a similar response time as those measured by collocated reference instruments. Overall, the study has shown that the SMOG units provide relevant information about ambient $\mathrm{PM}_{2.5}$ concentrations in an airshed impacted predominantly by biomass burning, provided that an adequate adjustment factor is applied.
\end{abstract}

Keywords: particulate matter; validation; smoke; sensors; STEM; air quality

\section{Introduction}

It is well understood that there are negative health impacts from exposures to biomass smoke [1-10]. With the increasing amount of time when bushfires and prescribed burns can occur, there is growing interest from the public on how to best measure and manage their exposures [11-14].

To capture the local movement of smoke associated with biomass burning events a dense spatial network of air quality monitors is needed $[15,16]$, which can be enhanced through the use of satellite-based data $[15,17,18]$. Considerable resources are required to maintain such a network of reference air quality monitors in regional locations where biomass smoke events most frequently occur [19]. In response to this resourcing issue, the use of 'low-cost' air quality sensors can provide a useful alternative to traditional reference air quality monitors. These sensors have the potential to provide high resolution air quality monitoring, both in time and space. Mallia et al. [16] highlighted how low-cost sensor networks can be used to characterize smoke plumes from wildfires and contribute to the evaluation of smoke transport models. Applications of low-cost sensor networks can also be extended to population exposure and health assessment $[15,20]$. 
The challenges that earlier research studies identified related to the use of low-cost particulate matter (PM) sensors were the lack of consistency between individual sensors, under or over reporting in comparison to reference methods and the deterioration in their performance over time [21,22]. Feinberg et al. [22] also called into question the consistency of the sensor performances based on meteorological conditions. The effects of elevated relative humidity $(\mathrm{RH})$ and temperature on sensor performance is divided, with some studies showing negative effects of RH on sensor performance [23] while others show minimal impact [24-26]. Zamora et al. [27] highlighted that low-cost PM sensors are more accurate in environments with polydispersed particle sources and for PM with less than $1 \mu \mathrm{m}$ diameter. Since then, more studies have investigated the performance of low-cost particle sensors under various particle loading scenarios and have established various calibration curves with or without environmental terms [26,28-30]. The Plantower PM sensors (PMS1003/3003/5003) have been tested against reference methods in several studies under laboratory conditions to assess the sensor's suitability and accuracy $[27,31-38]$ as well as in field-based measurements [20,24-26,29,30,39-43]. With the growing use of low-cost sensors both by the public and for research purposes, it is important to be able to interpret the data and understand their potential limitations [44].

With this understanding, we have conducted a number of field monitoring campaigns across regional Victoria. We selected locations impacted by both residential woodsmoke and planned burn emissions to evaluate the utility of the Plantower PMS3003 $[45,46]$ for use in the detection and monitoring of biomass smoke as part of a broader Science, Technology, Engineering and Mathematics (STEM) project.

We present results from a range of validation monitoring tests that have been conducted using the sensor to demonstrate its utility for conducting biomass monitoring and to provide a better understanding of what can be interpreted from the data.

Objectives:

- Develop a smoke-specific calibration curve for the low-cost sensor SMOG units developed in this study and test how the calibrated data set for $\mathrm{PM}_{2.5}$ compares against gravimetric mass measurements and reference instruments at three different locations and during different seasons.

- Assess the suitability of low-cost particle sensors to detect ambient smoke events and provide insights into the spatial and temporal patterns of these events.

- Develop a school STEM curriculum focusing on the construction, deployment and analysis of data from low-cost particle sensors to assess biomass burning impacts on regional air quality where regulatory air quality monitoring is sparse.

\section{Materials and Methods}

\subsection{Instruments}

The SMoke Observation Gadget (SMOG) is a unit that comprises of a Plantower Laser $\mathrm{PM}_{2.5}$ dust sensor (model PMS3003) $[45,46]$ and a digital temperature and humidity sensor (DHT22 AM2302). The PMS3003 uses a light scattering principle to measure particles suspended in the air. A red-coloured laser (wavelength of $650 \pm 10 \mathrm{~nm}$ [45]) shines light into a measuring cavity through which air is drawn by a fan. A photo-diode measures scattered light at a 90 degrees angle to the laser beam. Flow is not critical because there is no size selective inlet or means of collecting aerosol for gravimetric calibration. The amount of scattered light is measured by a photodiode detector to determine the mass concentrations of particles using a proprietary algorithm based on Mie Theory. The measuring cavity is designed to be a light trap, so that only scattered light falls onto the receptor. The Plantower PMS3003 provides continuous measurements of $\mathrm{PM}_{1}, \mathrm{PM}_{2.5}$ and $\mathrm{PM}_{10}$ concentrations with a response time of $10 \mathrm{~s}$. In this study, the raw standard $\mathrm{PM}_{2.5}$ output data from the PMS3003 (e.g., $\mathrm{CF}=1$ ) were used.

The SMOG unit has both a particle and temperature/humidity sensor that are interfaced via a printed circuit board (PCB) to a microcontroller, a Raspberry Pi Model 3B (RPi). The RPi receives information from the sensors and logs the data at 5-min intervals to an 
internal micro-SD card and an external USB stick. The electronics are consolidated onto a single PCB that connects directly to the RPi. All components are housed in a waterproof enclosure $(150 \times 200 \times 100 \mathrm{~mm})$ to facilitate outdoor deployment. Figure 1 shows an assembled SMOG unit. The unit also has a number of light-emitting diodes (LEDs). These indicate the operating status of the system at the start-up, and the particle load in the air during sampling. The overall design was simplified to ensure that Grade 6 students could construct and operate the monitor.

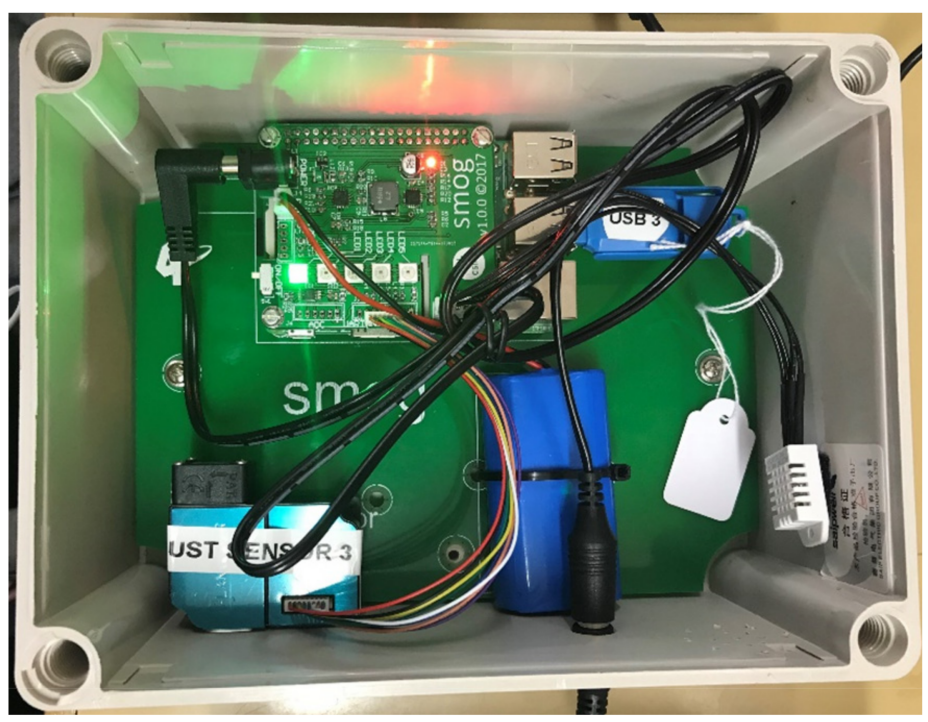

Figure 1. Assembled Smoke Observation Gadget (SMOG).

The SMOG units were tested at various locations and in different seasons alongside a tapered element oscillating microbalance (TEOM, Thermo Fisher Scientific, Waltham, MA, USA), an E-Sampler (Met One Instruments, Grants Pass, OR, USA) and a Fidas ${ }^{\circledR} 200 \mathrm{~S}$ (Palas GmbH, Karlsruhe, Germany).

The TEOM is an EPA-designated equivalent method used for real-time measurements of the mass concentrations of particles. Air is drawn through a filter resting on a microbalance at a known flow rate and the change in frequency of an oscillating microbalance relative to the blank filter weight determines the volumetric concentration of particulate matter in ambient air [47]. The measurement is only dependent on the mass of the particles (i.e., not density, chemical composition or optical or electrical properties). A filter dynamic measurement system (FDMS) is used to adjust for the volatile component of the mass.

The E-sampler contains a diode laser that operates at a $670 \mathrm{~nm}$ wavelength and measures real-time particles through near-forward light-scattering. Accurate flow in the E-sampler is critical to ensure accurate size selection through the inlet for gravimetric calibration of $\mathrm{PM}_{2.5}$. The E-samplers operate at a flow rate of $2 \mathrm{~L} / \mathrm{min}$ and collect both continuous particle measurements at a 5 min interval by light-scattering and particle mass on pre-weighed $47 \mathrm{~mm}$ Fluoropore membrane filters with a $1 \mu \mathrm{m}$ pore size (Merck Millipore, Darmstadt, Germany). The scattering is converted into mass concentration using a gravimetric K-factor determined from the aerosol mass collected on a filter during sampling. Although the E-sampler is not an EPA-designated equivalent method, applying a gravimetric K-factor generated for the E-sampler during the measurement period ensures that accurate concentration measurements and good agreement with federal reference methods (FRM) and federal equivalent methods (FEM) are achieved.

The Fidas ${ }^{\circledR} 200$ S, a European equivalent reference method, is an optical aerosol spectrometer that continuously analyzes ambient particles present in the size range $180 \mathrm{~nm}-$ $18 \mu \mathrm{m}$. It is equipped with a polychromatic LED light source and has a $90^{\circ}$ scattering angle. 
The TEOM, E-sampler and Fidas are all equipped with an aerosol drying system controlled by dynamic heating of the inlet to keep relative humidity of the intake air below $50 \%$. In addition to removing water, heating the intake air has the undesired effect of evaporating volatile PM. The TEOM is the only instrument to control for this using a filter dynamics measurement system. Operational settings of the various types of particle instruments are provided in Table 1. It should be noted that differences in wavelengths of the light source and scattering angles between instruments may impact on the sensor response. The E-sampler and PMS3003 use a similar light source but a different scattering angle while the Fidas has a similar scattering angle to the PMS3003 but uses a different light source.

Table 1. Operational settings of instruments.

\begin{tabular}{|c|c|c|c|c|}
\hline Parameters & SMOG & E-Sampler & Fidas & TEOM \\
\hline Sampling time (s) & 1 & 1 & 1 & 2 \\
\hline Size range $(\mu \mathrm{m})$ & $0.3-10$ & $0.1-100$ & $0.18-18$ & NA \\
\hline Resolution $\left(\mu \mathrm{g} \mathrm{m}^{-3}\right)$ & 1 & 1 & 0.1 & 0.1 \\
\hline Effective detection range $\left(\mu \mathrm{g} \mathrm{m}^{-3}\right)$ & $0-500$ & $0-65,000$ & $0-10,000$ & $0-1,000,000$ \\
\hline Flow rate (lpm) & NA & 2 & 4.8 & 3 \\
\hline Temperature range $\left({ }^{\circ} \mathrm{C}\right)$ & -10 to 60 & -30 to 50 & -20 to 50 & -40 to 60 \\
\hline Humidity range $(\%)$ & 0-99 & Drying system & Drying system & Drying system \\
\hline Light source wavelength & $650 \mathrm{~nm}$ & $670 \mathrm{~nm}$ & Polychromatic LED & NA \\
\hline Scattering angle & $90^{\circ}$ & forward & $85-95^{\circ}$ & NA \\
\hline PM sizing & Mie-scattering & Cyclone & Mie-scattering & $\mathrm{PM}_{2.5}$ inlet \\
\hline Weight (kg) & 0.04 & 6.4 & 9.3 & 18 \\
\hline Size (mm) & $38 \times 35 \times 12$ & $267 \times 235 \times 145$ & $180.5 \times 450 \times 320$ & $432 \times 483 \times 1400$ \\
\hline
\end{tabular}

\subsection{Measurement Locations}

We used the data set collected during a peat fire event near Port Macquarie, NSW (latitude -31.4337 , longitude 152.9153) to develop a smoke-specific calibration curve for the SMOG units. This event was chosen as it was a prolonged biomass burning particle pollution event that presented a wide range of particle concentrations. Two SMOG units were collocated alongside a standard regulatory method (FDMS-TEOM) between August and December 2019 to evaluate smoke impacts due to the nearby peat fires [48]. The monitoring equipment was set up at a mobile monitoring site operated by the NSW Department of Planning, Industry and Environment (DPIE). The site was located in the car park of a local library. Readings from the SMOG units were averaged on an hourly and $24 \mathrm{~h}$ basis for comparison with the TEOM and for the development of a smoke-specific calibration curve for the SMOG units.

A number of field-based measurements were conducted to test the suitability of the SMOG units to accurately detect and monitor biomass burning events in different locations and under different meteorological conditions (Table S1 and Figure S1).

Measurements were conducted on the rooftop of CSIRO laboratories at Aspendale, Victoria (latitude -38.025, longitude 145.102) located $30 \mathrm{~km}$ south of Melbourne and in close proximity ( $\sim 50 \mathrm{~m}$ ) to the Port Philip bay shoreline from 23 to 26 April 2018 (autumn) and between 25 June and 16 July 2018 (winter) (Figure S2). The area is impacted by local residential woodsmoke emissions during autumn/winter. In autumn, three SMOG units were compared to two collocated E-samplers fitted with a $\mathrm{PM}_{2.5}$ size-selective inlet and to the Fidas. In winter, one SMOG unit was collocated with an E-sampler fitted with a $\mathrm{PM}_{2.5}$ size-selective inlet and with the Fidas.

Ambient $\mathrm{PM}_{2.5}$ measurements using the low-cost sensor SMOG units were completed at fifteen locations in north-east Victoria between 1 May 2018 and 6 June 2018 and at six locations in north-east Victoria between November 2018 and June 2019 (Figure S1). The monitoring sites were located in areas that had the potential to be impacted by either prescribed burns, stubble burns or bushfires. Two SMOG units were deployed at each 
location. During each deployment period in north-east Victoria, reference instruments were installed at one location (e.g., Rutherglen in May/June 2018 and Alexandra between November 2018 and June 2019) to test the performance of the SMOG units either against the Fidas and/or the E-sampler.

The smoke-specific calibration curve parameters were applied to all deployed SMOG units with the hourly calibrated data set being compared against the reference instruments.

\subsection{Data Analysis}

A data cleaning criterion was applied to the raw data output from the SMOG units to remove erroneous data due to errors in PM filter sizing (e.g., check if $\mathrm{PM}_{10} \geq \mathrm{PM}_{2.5} \geq$ $\mathrm{PM}_{1}$ ) and unrealistic spikes or drops in temperature and $\mathrm{PM}_{2.5}$. The filtered data set was then aggregated to hourly averaged data using a $75 \%$ data capture.

The limit of detection (LOD) for the SMOG units was determined by using the method of Wallace et al. [49]. LOD has been defined as the lowest concentration at which the ratio of the mean to standard deviation exceeds 3 .

The following parameters were used to assess the performance of the SMOG units. Precision refers to how well all sensors reproduce the measurement of $\mathrm{PM}_{2.5}$ under identical circumstances. The precision of the SMOG units was evaluated using Pearson's Correlation Coefficient to understand the associations between SMOG units. We used the reduced major axis linear regression relationships in $\mathrm{R}$ to provide insight into the pattern and extent of agreement between SMOG units [50]. A perfect agreement between SMOG units would show a slope of 1 , indicating a similar response between the two instruments, and intercept of 0 , indicating no bias in the sensor's response. The intra-precision and accuracy of the SMOG units were also evaluated using Lin's Concordance Correlation Coefficient (CCC). The CCC measures the agreement of continuous measurements obtained by two different methods by determining how far the observed data deviate from the line of perfect concordance (e.g., 1:1 line) [51,52]. The CCC value increases as a function of the accuracy of the data and the precision of the data. All statistical analysis was conducted using the statistical packages epiR in R [53].

The performance of the SMOG units was evaluated by computing linear regression and correlation with a reference instrument (e.g., E-sampler, Fidas or TEOM) using Ordinary Least Squares (OLS) Linear Regression in R [54]. This provided the strength of the relationship and the suitability of the calibration curve for the SMOG units. Lin's concordance coefficient was also used to assess the precision and accuracy of the SMOG units relative to the reference instruments. Bland-Altman plots were used to examine the agreement between $\mathrm{PM}_{2.5}$ measurements made by the SMOG units and the corresponding reference particle instrument ( $R$ package 'BlandAltmanLeh' version 0.3.1) [55]. BlandAltman diagrams (or difference plots) are typically used for the visual comparison of two measurements methods.

Additionally, the relative bias, mean absolute error (MAE), root mean square error (RMSE) and normalised root mean square error (NRMSE) were calculated for each hourly data set to measure data accuracy using $R$ packages (Table S2).

\subsection{Development of STEM Project}

The SMOG units were designed to support a student-based project. The STEM project combined science, mathematics, engineering, and digital technology to address the issue of the impact of ambient particles from biomass burning sources on local and regional air quality and to assess air quality sensors. The project aimed to forecast smoke movements in smoke impacted regions and engage the community through schools.

The project was targeted at Grade 6-8 students and comprised of five lessons. The first three lessons were classroom based interactive presentations that taught students about air pollution and ambient particles, biomass burning and measurement techniques of ambient particles. 
Lesson 4 was a hands-on session when students worked in teams to build the SMOG. After building the SMOG unit the students undertook a monitoring campaign using the SMOG units. Ideally, the monitoring campaign captured a period of potential high particle concentrations in the air such as those that result from prescribed burning in autumn or from domestic wood smoke in winter. The students were encouraged to set up the SMOG units outside their home and monitor the ambient air over approximately a 4-to-6-week period. Once the monitoring campaign was finished, the students returned their units to school to process and analyse their collected data set as part of lesson 5 .

\section{Results and Discussion}

To evaluate the suitability of the SMOG units to capture and quantify smoke events, we assessed their performance against each other and against gravimetric mass measurements and reference instruments.

\subsection{Development of Calibration Curve for SMOG Units}

Previous studies have shown that the Plantower sensors correlated well with reference instruments, but they exhibited high biases [24,26,30,42,43,45]. In these studies, various simple and multi-variate linear regression curves as well as polynomial, exponential and quadratic correction equations were established for correcting $\mathrm{PM}_{2.5}$ concentrations.

We used hourly $\mathrm{PM}_{2.5}$ measurements from a FDMS-TEOM during a period of smoke from peat fires near Port Macquarie (NSW) to develop a calibration curve for the SMOG units. Ambient hourly $\mathrm{PM}_{2.5}$ concentrations up to $1300 \mu \mathrm{g} \mathrm{m}^{-3}$ were measured during the sampling period between August-December 2019. Figure 2 shows the fitted lines for the two measurements methods, with the relevant equations shown below.

$$
\begin{gathered}
\mathrm{PM}_{2.5}\left(\mu \mathrm{g} \mathrm{m}^{-3}\right)=1.667+0.569 \times \mathrm{SMOG} \\
\mathrm{PM}_{2.5}\left(\mu \mathrm{g} \mathrm{m}^{-3}\right)=0.578 \times \mathrm{SMOG} \\
\mathrm{PM}_{2.5}\left(\mu \mathrm{g} \mathrm{m}^{-3}\right)=5.45+0.45 \times \mathrm{SMOG}+1.2 \times 10^{-4} \times \mathrm{SMOG}^{2}+1.8 \times 10^{-7} \times \mathrm{SMOG}^{3}
\end{gathered}
$$

The data suggests that a linear relationship can be applied to correct the SMOG data up to an hourly $\mathrm{PM}_{2.5}$ concentration of $\sim 300 \mu \mathrm{g} \mathrm{m}^{-3}$, with a 3rd degree polynomial curve best fitted for $\mathrm{PM}_{2.5}$ concentrations exceeding $300 \mu \mathrm{g} \mathrm{m}^{-3}$. Previous studies have shown non-linear behaviour above concentrations as low as $25 \mu \mathrm{g} \mathrm{m}^{-3}$ [43] and $40 \mu \mathrm{g} \mathrm{m}^{-3}$ [42], while other studies have shown a linear relationship exists at concentrations up to $125 \mu \mathrm{g}$ $\mathrm{m}^{-3}$ [46], $150 \mu \mathrm{g} \mathrm{m}^{-3}$ [29] and $200 \mu \mathrm{g} \mathrm{m}^{-3}$ [26]. These differences could be due to particle composition, particle size and environmental conditions during testing, variations in the response of individual sensors or due to sensor algorithm $[45,46,56]$.

Our linear equations with zero and non-zero intercepts showed similar slopes (1.73 and 1.76) and no significant difference in RMSE. This was also observed by Delp and Singer [29] who used simple scalars with no offset as adjustment factors for wildfire smoke. The median adjustment factors calculated for the Purple Air (PA) units that include Plantower sensors PMS5003 ranged from 0.42 to 0.58 , in agreement with the adjustment factor of 0.58 in this study (defined as the slope in Equation (2)). The slopes we generated are also similar to the reported adjustment factor of 0.55 by Robinson [30] and the slopes by Holder et al. [26] (e.g., 0.51 for PA sensor and 0.57 for RAMP sensor). The slight difference in response between the PA and RAMP sensors (both units using the same Plantower PM sensor) was attributed to a potential difference in the sensor package design and/or post-processing algorithm [26]. 


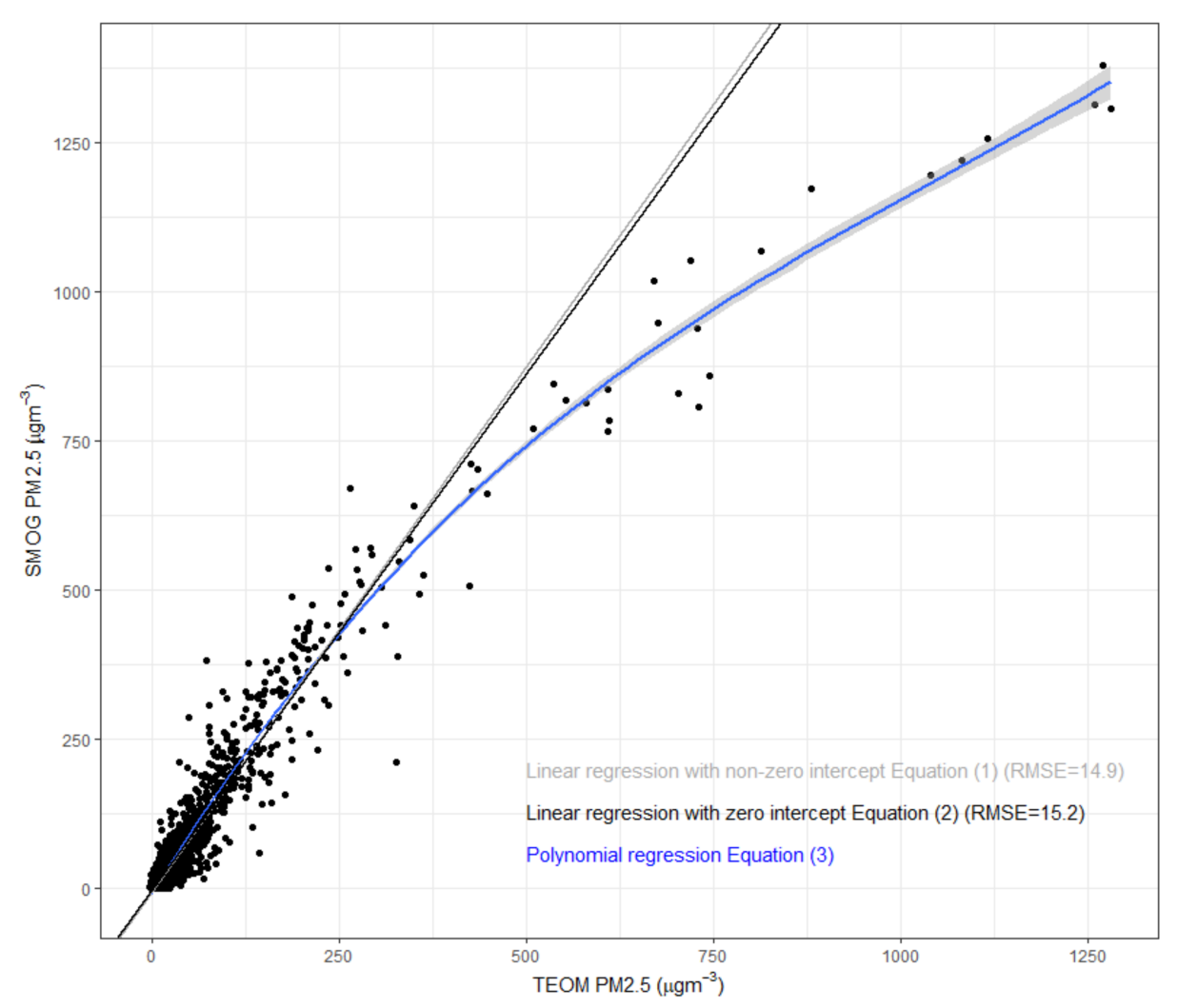

Figure 2. Fitted calibration curves for the SMOG units against the TEOM.

A linear multivariate regression with additive terms for temperature and relative humidity was also developed for the SMOG $\mathrm{PM}_{2.5}$ concentrations in the $0-600 \mu \mathrm{g} \mathrm{m}^{-3}$ range.

$$
\begin{gathered}
\mathrm{PM}_{2.5}\left(\mu \mathrm{g} \mathrm{m}^{-3}\right)=11.76+0.569 \times \mathrm{SMOG}-0.056 \times \text { temperature }\left({ }^{\circ} \mathrm{C}\right)-0.157 \times \mathrm{RH}(\%) \\
\mathrm{PM}_{2.5}\left(\mu \mathrm{g} \mathrm{m}^{-3}\right)=9.56+0.569 \times \mathrm{SMOG}-0.142 \times \mathrm{RH}(\%)
\end{gathered}
$$

A recent paper by Barkjohn et al. [28] developed an adjustment factor for the Purple Air Sensor that could be applied across the United States. After trialing a variety of model fits, the authors chose an additive RH model to work across a wide variety of data. Their fitted equation is similar to the one developed in this study (Equation (4)) with an approximate $8 \%$ difference. Holder et al. [26] observed little improvements in sensor accuracy when including an RH term and as a result recommended a simple regression without environmental terms.

\section{2. $\mathrm{PM}_{2.5}$ Measurement Statistics}

The LOD for $\mathrm{PM}_{2.5}$ measurements was calculated at $5.5 \mu \mathrm{g} \mathrm{m} \mathrm{m}^{-3}$, in agreement with the LOD of $6 \mu \mathrm{g} \mathrm{m}^{-3}$ reported by Barkjohn et al. [57] and Sayahi et al. [42] but higher than the LOD reported for PMS5003 [31,34,58].

There are several theories regarding the replacement of values below the LOD, either being censored or substituted with a constant value, such as half the LOD, the LOD divided by the square root of 2, or zero. Using either approach can have impacts on the analyses $[59,60]$. Depending on the percentage of values below the LOD, replacing values below the LOD can produce strong biases, questionable descriptive statistics and differences in correlation and regression relationships. Due to the variable number of values below the LOD, we retained the actual values to minimise introducing any bias in the analysis. 
Tables S3-S5 show the summary statistics of the hourly measurements conducted in the field-based measurements. Boxplots of hourly $\mathrm{PM}_{2.5}$ concentrations for each measurement period and collocation of instruments are shown in Figure S3.

During the rooftop test at Aspendale, 35-43\% of data were below the LOD, while for the field-based measurements in Northeast Victoria the percentage of hourly $\mathrm{PM}_{2.5}$ concentrations below LOD ranged from 32-89\%. More than $90 \%$ of hourly $\mathrm{PM}_{2.5}$ concentrations remained below $25 \mu \mathrm{g} \mathrm{m}^{-3}$. Maximum hourly $\mathrm{PM}_{2.5}$ concentrations ranged from 32 to $220 \mu \mathrm{g} \mathrm{m}^{-3}$. As the maximum hourly $\mathrm{PM}_{2.5}$ concentration was measured at $220 \mu \mathrm{g}$ $\mathrm{m}^{-3}$, we applied the linear calibration curve fitted through the origin to correct the hourly SMOG data for the field-based testing.

\subsection{Inter-Comparison of SMOG Units}

Intercomparison of collocated SMOG units enabled us to assess whether the SMOG units are suitable for measuring the spatial variability in $\mathrm{PM}_{2.5}$ concentrations. The summary of statistical metrics for the SMOG inter-comparisons is shown in Table 2.

Table 2. Statistical metrics of SMOG inter-comparison.

\begin{tabular}{|c|c|c|c|c|c|c|c|c|c|c|}
\hline $\begin{array}{l}\text { Measurement } \\
\text { Period }\end{array}$ & $\begin{array}{l}\text { SMOG } \\
\text { ID }\end{array}$ & Slope & Intercept & $r^{2}$ & RMSE & NRMSE & Bias & MAE & $\mathrm{CCC}$ & $\mathbf{N}(\mathrm{h})$ \\
\hline \multirow{8}{*}{$\begin{array}{c}\text { Aspendale } \\
\text { autumn (2018) }\end{array}$} & 2 vs. 3 & 0.84 & 0.95 & 0.94 & 2.06 & 26.4 & 0.33 & 1.71 & 0.95 & 72 \\
\hline & 2 vs. 4 & 1.03 & 0.41 & 0.98 & 1.32 & 16.9 & -0.67 & 0.96 & 0.98 & 72 \\
\hline & 4 vs. 3 & 0.81 & 0.62 & 0.94 & 2.43 & 28.7 & 1.00 & 1.93 & 0.94 & 72 \\
\hline & 23 vs. 25 & 0.98 & -0.01 & 0.98 & 0.70 & 20.0 & -0.09 & 0.39 & 0.99 & 831 \\
\hline & 15 vs. 21 & 1.00 & 0.15 & 0.98 & 0.67 & 15.5 & 0.14 & 0.36 & 0.99 & 775 \\
\hline & 3 vs. 24 & 1.03 & -0.10 & 0.74 & 3.07 & 82.6 & 0.01 & 1.24 & 0.86 & 792 \\
\hline & 1 vs. 30 & 0.99 & -0.77 & 0.97 & 1.76 & 26.5 & -0.84 & 1.03 & 0.98 & 614 \\
\hline & 22 vs. 28 & 0.82 & -0.10 & 0.93 & 1.57 & 51.1 & -0.82 & 0.87 & 0.92 & 820 \\
\hline NE Victoria & 6 vs. 7 & 0.99 & -0.08 & 0.99 & 0.63 & 9.7 & -0.15 & 0.39 & 1.00 & 72 \\
\hline \multirow[t]{6}{*}{ May-June 2018} & 12 vs. 13 & 0.96 & -0.05 & 0.99 & 0.74 & 16.8 & -0.24 & 0.41 & 0.99 & 855 \\
\hline & 2 vs. 4 & 0.85 & -0.16 & 0.93 & 1.18 & 64.2 & -0.51 & 0.52 & 0.94 & 855 \\
\hline & 16 vs. 17 & 1.09 & 0.27 & 0.99 & 0.93 & 22.2 & 0.60 & 0.61 & 0.99 & 828 \\
\hline & 18 vs. 19 & 0.97 & 0.04 & 0.99 & 0.85 & 11.9 & -0.15 & 0.52 & 1.00 & 825 \\
\hline & 8 vs. 9 & 0.97 & 0.74 & 0.97 & 1.98 & 22.4 & 0.53 & 0.80 & 0.98 & 849 \\
\hline & 10 vs. 11 & 0.97 & -0.34 & 0.99 & 1.33 & 18.5 & -0.59 & 0.84 & 0.99 & 855 \\
\hline \multirow{5}{*}{$\begin{array}{c}\text { NE Victoria } \\
\text { November 2018- } \\
\text { June } \\
2019\end{array}$} & 6 vs. 15 & 0.93 & -0.25 & 0.99 & 2.12 & 25.7 & -0.64 & 0.88 & 0.99 & 2502 \\
\hline & 2 vs. 14 & 1.04 & -0.19 & 0.99 & 1.91 & 76.0 & 0.13 & 0.77 & 1.00 & 2573 \\
\hline & 3 vs. 41 & 0.91 & -0.44 & 0.93 & 2.45 & 48.3 & -0.80 & 1.25 & 1.00 & 1607 \\
\hline & 9 vs. 26 & 1.11 & -0.09 & 0.86 & 2.72 & 45.9 & 0.45 & 1.02 & 1.00 & 1384 \\
\hline & 7 vs. 10 & 0.96 & -0.41 & 0.96 & 2.22 & 25.7 & -0.63 & 0.96 & 0.98 & 3360 \\
\hline
\end{tabular}

Agreement between SMOG units 2 and 4 during the autumn measurements at Aspendale was very high $\left(\mathrm{r}^{2}=0.98\right.$, slope $=1.03$, intercept $\left.=0.41\right)$ and CCC value of 0.98 (Table 2). The good agreement between the two SMOG units is shown in the Bland-Altman plot in Figure S4 (mean bias of $0.67 \mu \mathrm{g} \mathrm{m}^{-3}$ and agreement limits between -1.57 and $2.91 \mu \mathrm{g} \mathrm{m}^{-3}$ ). SMOG unit 3 did not perform as well with an under-reporting of $\sim 20 \%$, this was potentially due to drift in the sensor performance.

The collocation of two SMOG units at each of the sites in Northeast Victoria enabled us to further test the measurement agreement between SMOG units. The results were variable with very good agreement for most sites and units and very high CCC values indicating significant reliability (Table 2). We excluded any units for which sampling issues were identified, including unit 5 that showed much lower levels than other tested units, unit 20 that showed unrealistically high $\mathrm{PM}_{2.5}$ values likely due to an insect in the dust sensor which affected the sensor readings and unit 27 that switched off after $7 \mathrm{~h}$. Poorer performance was observed at concentrations below $10 \mu \mathrm{g} \mathrm{m}^{-3}$. Examples of scatter and Bland-Altman plots are shown in Figure S5 highlighting the variable agreements. Possible explanations for the poorer performance between SMOG units include drift in sensor 
performance (as reported by Sayahi et al. [42] and Wang et al. [36]); misalignment of the sensor inlet with the inlet hole of the enclosure; very localized sources (e.g., SMOG2\&4 in NE Victoria were deployed indoors and were potentially more sensitive to location).

The rooftop tests conducted at CSIRO Aspendale and the collocated SMOG units at north-east Victoria have shown an overall good intra-precision between SMOG units. Previous studies have shown very high correlations between PMS3003 units. For example, Zheng et al. [46] reported $\mathrm{r}^{2}$ values of $0.98-1.0$ among five PMS3003 units, while Kelly et al. [45] showed high correlations $\left(\mathrm{r}^{2}>0.99\right)$ between two PMS3003 units.

The data suggest that the SMOG units are reliable over a range of concentrations, temperatures $\left(5-50{ }^{\circ} \mathrm{C}\right)$, and $\mathrm{RH}$ values (11-91\%) which suggests they can be deployed to assess the spatial variability of $\mathrm{PM}_{2.5}$ concentrations in a wide range of locations and conditions.

\subsection{Evaluation of $P M_{2.5}$ Measurements Made by Optical Instruments versus Gravimetric Mass} Measurements

Regression analysis of the continuous measurements by light-scattering versus gravimetric mass measurements for the E-sampler and Fidas are provided in Table 3 and Figure S6.

Comparison of gravimetric mass measurements against averaged corrected SMOG data showed ratios varying between 0.69 and 1.48 (excluding time periods with less than $50 \%$ data capture and more than $90 \%$ of data below LOD). The corrected SMOG data measured at Rutherglen were within $10 \%$ of the gravimetric mass measurements. Most of the SMOG data measured during the summer at Alexandra were below the LOD, with averaged corrected SMOG data being lower than the gravimetric mass measurements. In April, corrected SMOG data was in good agreement with the gravimetric mass measurements, while higher $\mathrm{PM}_{2.5}$ concentrations compared to gravimetric mass measurements were observed in winter (May-June) at Alexandra. A similar trend was observed for the measurements with the Fidas and E-sampler. Lower ratios were observed in winter at both Aspendale and Alexandra when high concentrations of particle events were attributed to residential wood smoke. This trend is in agreement with the findings by Kelly et al. [45] and Tryner et al. [35] who reported an overestimation in sensor data compared to TEOM data when the sensor was exposed to wood smoke.

The results in Table 3 show that the Fidas over-reported $\mathrm{PM}_{2.5}$ concentrations compared to gravimetric mass measurements, while the E-sampler under-reported $\mathrm{PM}_{2.5}$ concentrations compared to gravimetric mass measurements except for measurements completed in winter at Aspendale and Alexandra.

Systematic discrepancies between light-scattering monitors and reference methods have been observed in previous research studies [61-63]. The over-estimation in $\mathrm{PM}_{2.5}$ concentrations has been attributed to the differences between the optical properties of the manufacturer's factory calibration particles and wood smoke particles and can be adjusted using a site-specific or season-specific calibration factor. The data also shows that there is not a uniform response of the light-scattering instruments to the different particle sources. This will be further explored in Section 3.6. 
Table 3. Comparison between gravimetric $\mathrm{PM}_{2.5}$ mass concentrations and $\mathrm{PM}_{2.5}$ concentrations measured using optical instruments, including raw and calibrated SMOG data.

\begin{tabular}{|c|c|c|c|c|c|c|c|c|c|c|c|c|c|}
\hline \multirow[t]{2}{*}{ Location } & \multirow[t]{2}{*}{ Date } & \multirow{2}{*}{$\begin{array}{c}\text { Gravimetric } \\
\left(\mu \mathrm{g} \mathrm{m}^{-3}\right)\end{array}$} & \multicolumn{5}{|c|}{ SMOG } & \multicolumn{3}{|c|}{ Fidas } & \multicolumn{3}{|c|}{ E-Sampler } \\
\hline & & & $\begin{array}{l}\text { Average }{ }^{1} \\
\left(\mu \mathrm{g} \mathrm{m}^{-3}\right)\end{array}$ & $\begin{array}{l}\text { Average (OLS) } \\
\quad\left(\mu \mathrm{g} \mathrm{m}^{-3}\right)\end{array}$ & $\mathrm{CF}^{3}$ & $\begin{array}{c}\text { Missing Data } \\
(\%)\end{array}$ & $<\operatorname{LOD}(\%)$ & $\begin{array}{c}\text { Average } \\
\left(\mu \mathrm{g} \mathrm{m}^{-3}\right)\end{array}$ & CF & $\begin{array}{c}\text { Missing Data } \\
(\%)\end{array}$ & $\begin{array}{c}\text { Average } \\
\left(\mu \mathrm{g} \mathrm{m}^{-3}\right)\end{array}$ & CF & $\begin{array}{c}\text { Missing Data } \\
\text { (\%) }\end{array}$ \\
\hline \multirow[t]{3}{*}{ Aspendale } & $25 / 06 / 18-02 / 07 / 18$ & 9.34 & 39.3 & 22.7 & 0.41 & 64 & 4 & 17.9 & 0.52 & 0 & 12.1 & 0.77 & 0 \\
\hline & $02 / 07 / 18-09 / 07 / 18$ & 3.42 & $\mathrm{na}^{4}$ & na & na & na & na & 7.4 & 0.46 & 0 & 4.8 & 0.71 & 0 \\
\hline & $09 / 07 / 18-16 / 07 / 18$ & 7.25 & na & na & na & na & na & 10.8 & 0.67 & 0 & 4.9 & 1.49 & 0 \\
\hline \multirow{4}{*}{ Rutherglen $^{5}$} & $01 / 05 / 18-21 / 05 / 18$ & 4.71 & 7.12 & 4.12 & 1.15 & 3.8 & 69 & na & na & na & 3.59 & 1.31 & 0 \\
\hline & $21 / 05 / 18-06 / 06 / 18$ & 4.41 & 6.90 & 3.99 & 1.10 & 6.1 & 64 & na & na & na & 3.39 & 1.30 & 0 \\
\hline & $01 / 05 / 18-21 / 05 / 18$ & 4.60 & 7.12 & 4.12 & 1.12 & 3.8 & 69 & na & na & na & 4.00 & 1.15 & 0 \\
\hline & $21 / 05 / 18-06 / 06 / 18$ & 4.33 & 6.90 & 3.99 & 1.08 & 6.1 & 64 & na & na & na & 3.55 & 1.22 & 0 \\
\hline \multirow[t]{9}{*}{ Alexandra } & $29 / 11 / 18-09 / 12 / 18$ & 4.44 & 1.63 & 0.94 & 4.71 & 10 & 92 & 4.83 & 0.92 & 11 & 1.85 & 2.40 & 0 \\
\hline & $18 / 12 / 18-27 / 12 / 18$ & 3.77 & 6.79 & 3.92 & 0.96 & 81 & 68 & 4.20 & 0.90 & 4.7 & 2.02 & 1.87 & 0 \\
\hline & $02 / 01 / 19-12 / 01 / 19$ & 4.48 & 2.75 & 1.59 & 2.82 & 11 & 95 & 5.85 & 0.77 & 13 & 2.71 & 1.65 & 0 \\
\hline & $16 / 01 / 19-06 / 02 / 19$ & 6.76 & 8.75 & 5.05 & 1.34 & 2.0 & 79 & 11.8 & 0.58 & 0 & 5.13 & 1.32 & 0 \\
\hline & $06 / 02 / 19-04 / 03 / 19$ & 4.52 & 2.88 & 1.66 & 2.72 & 49 & 91 & 6.84 & 0.66 & 2.5 & 2.82 & 1.60 & 2.7 \\
\hline & $21 / 03 / 19-05 / 04 / 19$ & 4.70 & 5.48 & 3.17 & 1.48 & 0 & 87 & 7.62 & 0.62 & 0.6 & 3.88 & 1.21 & 0.6 \\
\hline & $05 / 04 / 19-18 / 04 / 19$ & 7.32 & 13.2 & 7.62 & 0.96 & 26 & 54 & 15.6 & 0.47 & 33 & 5.86 & 1.25 & 20 \\
\hline & $18 / 04 / 19-16 / 05 / 19$ & 7.36 & 16.15 & 9.33 & 0.79 & 0 & 57 & 15.5 & 0.48 & 0 & 9.85 & 0.75 & 0 \\
\hline & $16 / 05 / 19-13 / 06 / 19$ & 12.03 & 30.2 & 17.4 & 0.69 & 3.1 & 46 & 24.4 & 0.49 & 0.1 & 18.1 & 0.66 & 0 \\
\hline
\end{tabular}

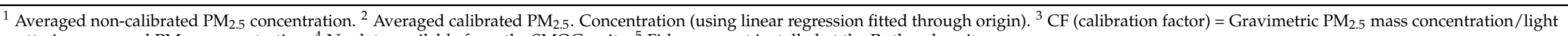
scattering averaged $\mathrm{PM}_{2.5}$ concentration. ${ }^{4}$ No data available from the SMOG units. ${ }^{5}$ Fidas was not installed at the Rutherglen site. 


\subsection{Performance Assessment of SMOG Units}

To check the accuracy of the SMOG units, we compared the hourly $\mathrm{PM}_{2.5}$ concentrations measured with the calibrated SMOG units using gravimetrically corrected measurements from the collocated Fidas (Fidas_CF) and E-sampler. Table 4 shows a summary of the statistical parameters using the different calibration curves for the SMOG calibration as defined in Section 3.1. The data shows that there is a minimal difference between the different calibration curves. Therefore, we used the calibration curve with zero intercept (Equation (2)) for the remaining analysis of the data sets. Table 4 also shows the statistical analysis of site- and season-specific intercomparison using Equation (2). Intercomparisons between calibrated SMOG (using Equation (2)), Fidas and E-sampler are shown in Figure 3.

Table 4. Performance of calibrated SMOG units in comparison to gravimetrically corrected reference instruments.

\begin{tabular}{|c|c|c|c|c|c|c|c|c|c|c|}
\hline SMOG Calibration & $\begin{array}{l}\text { Reference } \\
\text { Instrument }\end{array}$ & Slope & Intercept & $\mathbf{r}^{2}$ & $\begin{array}{c}\text { Slope } \\
\text { (Zero Int) }\end{array}$ & $\mathbf{r}^{2}$ & RMSE & $\underset{(\%)}{\text { NRMSE }}$ & MBE & MAE \\
\hline \multirow{2}{*}{$\begin{array}{c}\text { Linear with zero intercept (all } \\
\text { data) (Equation (2)) }\end{array}$} & E-sampler & 0.88 & 0.55 & 0.87 & 0.90 & 0.90 & 4.76 & 67.3 & -0.29 & 2.50 \\
\hline & Fidas & 1.43 & -2.53 & 0.95 & 1.30 & 0.94 & 5.17 & 74.6 & 0.52 & 2.98 \\
\hline \multirow{2}{*}{$\begin{array}{l}\text { Linear with non-zero intercept } \\
\text { (all data) (Equation (1)) }\end{array}$} & E-sampler & 0.87 & 2.15 & 0.87 & 0.94 & 0.90 & 4.90 & 69.3 & 1.20 & 2.82 \\
\hline & Fidas & 1.40 & -0.88 & 0.95 & 1.36 & 0.96 & 5.33 & 76.9 & 2.00 & 2.69 \\
\hline \multirow{2}{*}{$\begin{array}{l}\text { Polynomial (all data) } \\
\text { (Equation (3)) }\end{array}$} & E-sampler & 0.71 & 5.71 & 0.88 & 0.89 & 0.83 & 6.39 & 90.3 & 3.66 & 5.03 \\
\hline & Fidas & 1.15 & 3.23 & 0.95 & 1.32 & 0.95 & 5.22 & 75.3 & 4.31 & 4.40 \\
\hline \multirow{2}{*}{$\begin{array}{l}\text { Linear with additive RH term (all } \\
\text { data) (Equation (5)) }\end{array}$} & E-sampler & 0.82 & 3.17 & 0.83 & 0.91 & 0.86 & 5.81 & 82.2 & 1.84 & 3.84 \\
\hline & Fidas & 1.33 & 0.58 & 0.94 & 1.36 & 0.96 & 5.33 & 76.9 & 2.93 & 3.49 \\
\hline \multirow{2}{*}{$\begin{array}{l}\text { Linear with additive RH and } \\
\text { temperature term (all data) } \\
\text { (Equation (4)) }\end{array}$} & E-sampler & 0.82 & 3.40 & 0.84 & 0.93 & 0.86 & 5.77 & 81.6 & 2.11 & 3.88 \\
\hline & Fidas & 1.34 & 0.72 & 0.94 & 1.37 & 0.96 & 5.42 & 78.2 & 3.12 & 3.56 \\
\hline \multirow{2}{*}{ Aspendale autumn (Equation (2)) } & E-sampler & 0.80 & 0.68 & 0.78 & 0.85 & 0.90 & 4.02 & 41.5 & -1.22 & 3.42 \\
\hline & Fidas & 1.61 & -3.80 & 0.93 & 1.24 & 0.94 & 3.45 & 45.2 & 0.83 & 2.33 \\
\hline \multirow{2}{*}{ Aspendale winter (Equation (2)) } & E-sampler & 1.60 & 1.67 & 0.84 & 1.69 & 0.91 & 11.0 & 139 & 6.63 & 6.84 \\
\hline & Fidas & 2.29 & -3.62 & 0.96 & 2.04 & 0.97 & 11.9 & 146 & 6.80 & 7.25 \\
\hline \multirow{3}{*}{$\begin{array}{l}\text { Rutherglen (Equation (2)) } \\
\text { Alexandra summer-autumn } \\
\text { (Equation (2)) }\end{array}$} & E-sampler & 0.90 & 0.12 & 0.76 & 0.92 & 0.87 & 2.08 & 50.0 & -0.27 & 1.41 \\
\hline & E-sampler & 0.88 & 0.05 & 0.81 & 0.88 & 0.85 & 3.66 & 74.5 & -0.56 & 2.13 \\
\hline & Fidas & 1.23 & -2.18 & 0.92 & 1.05 & 0.91 & 2.81 & 54.7 & -0.96 & 2.07 \\
\hline \multirow{2}{*}{ Alexandra winter (Equation (2)) } & E-sampler & 0.84 & 2.54 & 0.91 & 0.89 & 0.94 & 7.81 & 41.5 & -0.26 & 4.22 \\
\hline & Fidas & 1.45 & -1.25 & 0.98 & 1.41 & 0.99 & 8.66 & 64.8 & 4.53 & 5.50 \\
\hline
\end{tabular}

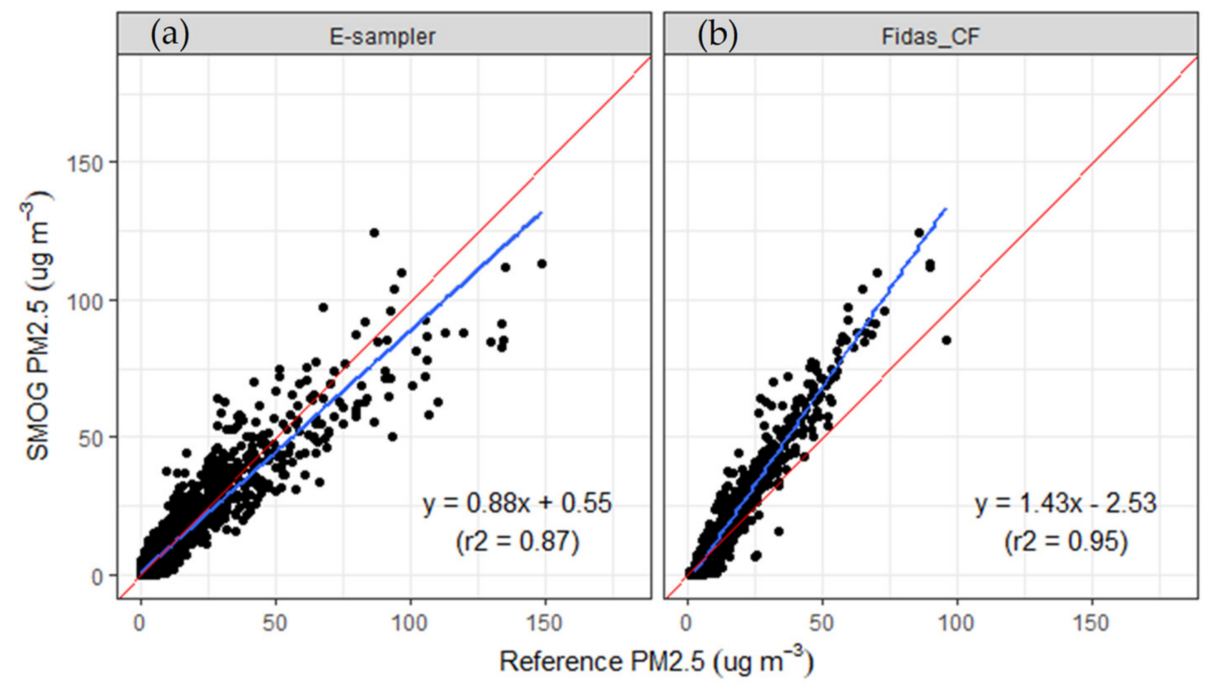

Figure 3. Scatterplot of hourly $\mathrm{PM}_{2.5}$ concentrations measured with the SMOG units compared to (a) the E-sampler and (b) Fidas_CF (both of which have been corrected against gravimetric mass measurements). Blue lines show linear least-squares fit; red line represents 1:1 line.

The SMOG units showed very good correlation with the E-sampler, with a slope of 0.88 , intercept of 0.55 and a CCC value of 0.93 . The SMOG units exhibited a bias within $10 \mu \mathrm{g} \mathrm{m}^{-3}$ with a larger bias observed at higher ambient $\mathrm{PM}_{2.5}$ concentrations (Figure 4). This variability seems in agreement with the reported consistency of $\pm 10 \mu \mathrm{g}$ $\mathrm{m}^{-3}$ at concentrations ranging from $0-100 \mu \mathrm{g} \mathrm{m}^{-3}$ reported for the Plantower sensors [64]. 
At higher $\mathrm{PM}_{2.5}$ concentrations, the SMOG units reported lower $\mathrm{PM}_{2.5}$ concentrations compared to the E-sampler.
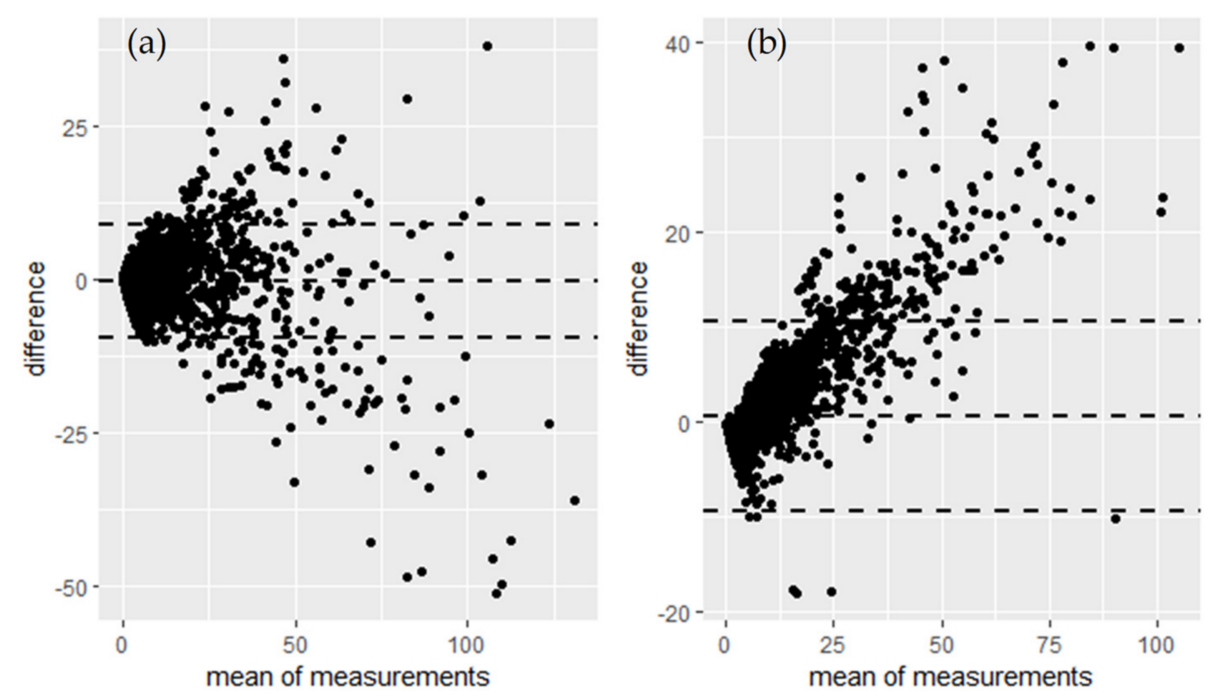

Figure 4. Bland-Altman plots of hourly $\mathrm{PM}_{2.5}$ concentrations measured with the SMOG units compared to (a) the E-sampler and (b) Fidas, both corrected against the gravimetric mass measurements.

The correlation between the SMOG and Fidas was very high $\left(\mathrm{r}^{2}=0.95\right)$, with an overreporting compared to gravimetrically corrected Fidas data (slope of 1.43). Similarly to the E-sampler, the Bland-Altman plot (Figure 4) shows agreement limits within $10 \mu \mathrm{g} \mathrm{m}^{-3}$ and a proportional difference variability between the $\mathrm{PM}_{2.5}$ concentrations measured by the SMOG unit and the Fidas, with a widening trend of agreement as $\mathrm{PM}_{2.5}$ concentrations increased over $25 \mu \mathrm{g} \mathrm{m}^{-3}$. An increase in the absolute bias with increased ambient $\mathrm{PM}_{2.5}$ concentrations has also been reported by Gupta et al. [15].

Unlike the SMOG units, the E-sampler and Fidas are fitted with a drier in the inlet to remove excess water from the air and keep the relative humidity below $50 \%$. As the SMOG sensors are based upon light scattering principles, particle hygroscopic properties can affect mass concentration estimations. Multivariate regression analysis conducted in this study has shown that changes in RH were significantly associated to changes in $\mathrm{PM}_{2.5}$. The association between temperature and $\mathrm{PM}_{2.5}$ concentrations was less consistent. However, using the multivariate regression analysis developed for the calibration curve of the SMOG vs. TEOM did not significantly alter the regression parameters and hence the sensor accuracy (Table 4). A similar observation was made by Holder et al. [26] who recommended using a simple linear regression to correct the data from the PA sensors, and other field-based evaluations of Plantower sensors [24,25,42]. The low insensitivity of the SMOG units to RH may be due to the low hygroscopicity of smoke particles [65].

Plotting the SMOG data vs. the reference data by location and season shows a closer fit for autumn at all locations compared to winter (Figure 5). Statistical metrics also showed a poorer agreement between SMOGs and reference instruments with a NRMSE above 100\% observed during winter at Aspendale as well as higher RMSE and MAE values observed during winter at both Aspendale and Alexandra (Table 4).

Correlations between SMOG units and E-sampler during the Aspendale autumn campaign were high $\left(r^{2}=0.77-0.91\right)$, with an average slope of 0.80 and intercept of 0.68 . The agreement between SMOG units and E-sampler was good (CCC values of 0.83 to 0.87 ). Performance of the SMOG unit against the Fidas was good, with a poorer performance for SMOG3 (possibly as a result of drift in sensor performance). Overall, the SMOG units over-reported by $\sim 40 \%$ when using Fidas data corrected against gravimetric mass measurements. 


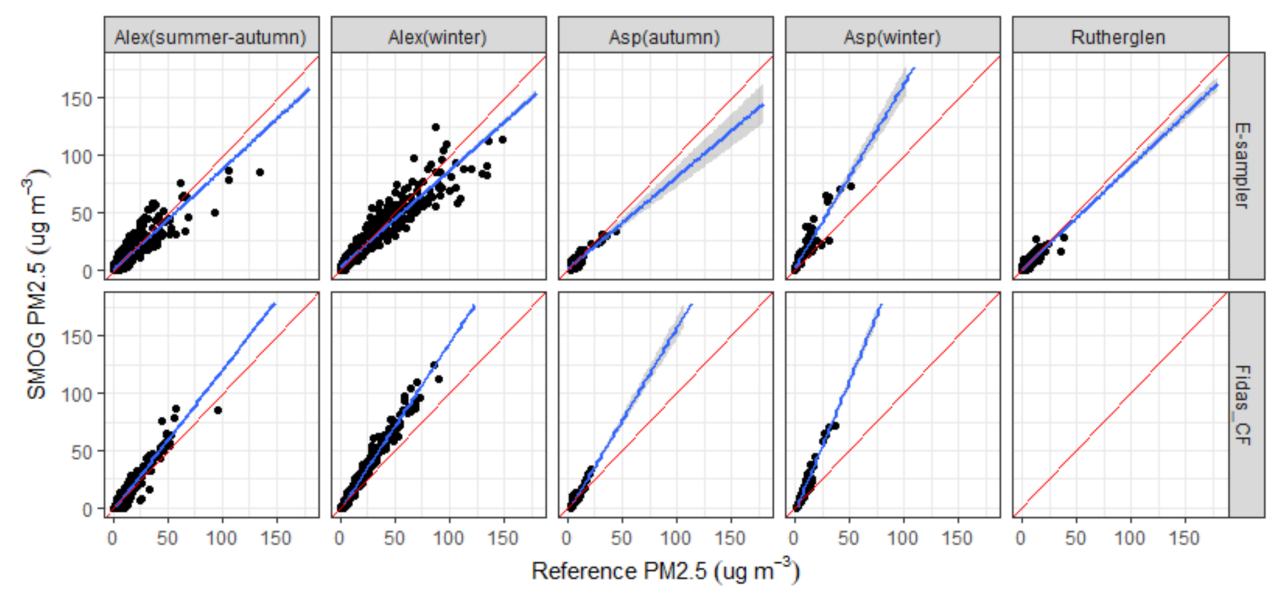

Figure 5. Scatterplot of hourly $\mathrm{PM}_{2.5}$ concentrations measured with the SMOG units compared to the E-sampler and Fidas_CF (both of which have been corrected against gravimetric mass measurements) by season and location. Blue lines show linear least-squares fit; red line represents 1:1 line.

The set of measurements conducted at Aspendale in winter 2018 showed high correlations between the SMOG unit and the E-sampler $\left(\mathrm{r}^{2}=0.84\right.$, slope of 1.60 and an intercept of $1.67)$ and the Fidas $\left(r^{2}=0.96\right.$, slope of 2.29, intercept of -3.62$)$. However, the SMOG units over-reported $\mathrm{PM}_{2.5}$ concentrations, with agreement limits ranging from -15.6 to $15.0 \mu \mathrm{g}$ $\mathrm{m}^{-3}$ for the E-sampler and from -9.9 to $19 \mathrm{\mu g} \mathrm{m}^{-3}$ for the Fidas.

Good correlation (average $\mathrm{r}^{2}$ value of 0.76 ) was observed between the two E-samplers and the two SMOG units at the location in Rutherglen, Victoria with slopes ranging between 0.88 and 0.96 . The scatter plots between SMOG7 and E-samplers indicate a large scatter when $\mathrm{PM}_{2.5}$ concentrations were below $10 \mu \mathrm{g} \mathrm{m}^{-3}$ and an underestimation of $\mathrm{PM}_{2.5}$ when concentrations were above $15 \mu \mathrm{g} \mathrm{m}^{-3}$ (Figure 5). The trend is similar to what was observed during autumn at Aspendale.

At Alexandra, we observed a larger scatter in the E-sampler vs. SMOG data set with slightly higher $\mathrm{PM}_{2.5}$ concentrations measured by the SMOGs in autumn and lower $\mathrm{PM}_{2.5}$ concentrations measured in winter. Less scatter is observed in the Fidas vs. SMOG data set with the SMOG data aligning with the corrected Fidas data up to a $\mathrm{PM}_{2.5}$ concentration of $\sim 25 \mu \mathrm{g} \mathrm{m}^{-3}$ and an over-reporting in $\mathrm{PM}_{2.5}$ concentrations above $25 \mu \mathrm{g} \mathrm{m}^{-3}$ with the over-reporting more pronounced in winter compared to summer-autumn.

Overall, the SMOG units exhibited a high correlation with reference instruments $\left(r^{2}>0.75\right)$. Bias and error values were within recommended performance metrics [66], except for winter.

Observed correlations in this study were higher compared to other field-based studies using the Plantower sensor [67]. Moderate correlations $\left(\mathrm{r}^{2}\right.$ of 0.40$)$ were reported by Zheng for hourly $\mathrm{PM}_{2.5}$ measurements made with the Plantower PMS3003 sensor and an E-BAM reference instrument, with improved correlations when averaging times were increased

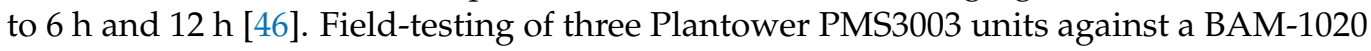
(Met one Instruments) conducted by the South Coast Air Quality Management District (SCAQMD) provided $\mathrm{r}^{2}$ values of 0.58 for hourly $\mathrm{PM}_{2.5}$ measurements [68]. Liu also reported moderate to good correlations (0.44-0.91) with performance varying by location and particle sources [40]. Poorer performance was observed for marine aerosols and fresh vehicle emissions with a better response to mixed urban background emissions, aged traffic emissions and industrial emissions. Higher correlations ( $\mathrm{r}^{2}$ of $\left.0.83-0.92\right)$ between PMS units and FEMs were reported in studies where biomass burning was the dominant particle source $[26,29,45]$ as was the case in this study.

Time series plots of hourly $\mathrm{PM}_{2.5}$ concentrations measured with the calibrated SMOG units compared with a reference instrument (E-sampler/Fidas) corrected against gravimetric mass measurements are shown in Figure 6 for Aspendale autumn, Aspendale winter, Rutherglen and Alexandra summer and Alexandra autumn/winter. 

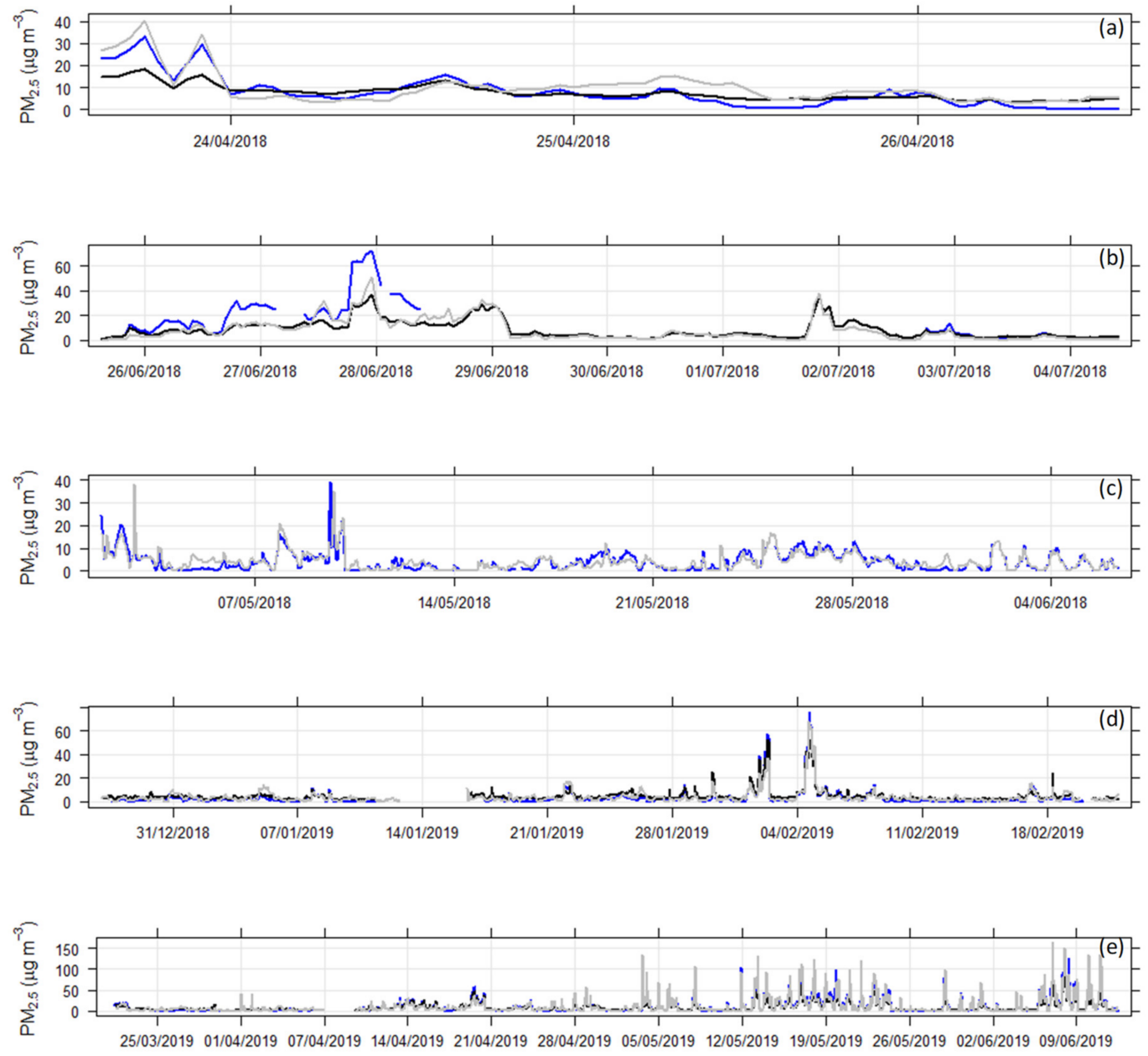

- SMOG Fidas E-sampler

Figure 6. Hourly time series of ambient $\mathrm{PM}_{2.5}$ concentrations at the four measurement locations in different seasons: (a) Aspendale autumn, (b) Aspendale winter, (c) Rutherglen, (d) Alexandra summer, (e) Alexandra autumn-winter.

The time series plots show that the SMOG units closely follow the $\mathrm{PM}_{2.5}$ trends of the collocated E-sampler and Fidas, indicating that the response time of the SMOG units is comparable to that of the E-sampler/Fidas and that peaks are temporally captured correctly.

\subsection{Capturing Smoke Plume Events}

At Aspendale in winter, we observed an elevated $\mathrm{PM}_{2.5}$ event on 27-28 June 2018 when the SMOG, Fidas and E-sampler were operational. Hourly $\mathrm{PM}_{2.5}$ concentrations remained above $25 \mu \mathrm{g} \mathrm{m}^{-3}$ for $15 \mathrm{~h}$.

In Rutherglen, we observed a short spike in $\mathrm{PM}_{2.5}$ concentrations on 3 May 2018 and elevated $\mathrm{PM}_{2.5}$ concentrations between 8-10 May 2018. Elevated $\mathrm{PM}_{2.5}$ concentrations were measured at the other sampling sites during May 2018 and were either attributed to planned burns or stubble burns.

During the 2018/19 measurement period, three major $\mathrm{PM}_{2.5}$ peak events were identified: 1-8 February 2019, 7-20 March 2019 and 14-22 April 2019 (Figure 7). In early February, the Alexandra site recorded increased hourly $\mathrm{PM}_{2.5}$ concentrations with a maximum peak concentration of $75 \mu \mathrm{g} \mathrm{m}^{-3}$ recorded on 4 February. Increased $\mathrm{PM}_{2.5}$ concentrations were also measured at Mansfield, Milawa and Tallangatta. The elevated $\mathrm{PM}_{2.5}$ concentrations were likely due to fires to the southeast of Alexandra. On 13-18 March, smoke plumes from fires to the east impacted the monitoring sites at Mansfield, Benalla and Milawa. Tallangatta also showed increased $\mathrm{PM}_{2.5}$ concentrations during March but trends in $\mathrm{PM}_{2.5}$ 
concentrations differed to the other monitoring sites suggesting that smoke impacting Tallangatta originated from different fires. Elevated $\mathrm{PM}_{2.5}$ concentrations observed at monitoring sites in April are likely due to nearby planned burns. Maximum hourly $\mathrm{PM}_{2.5}$ concentrations that were measured during the 2018/19 field campaign ranged from 32 to $220 \mu \mathrm{g} \mathrm{m}^{-3}$.

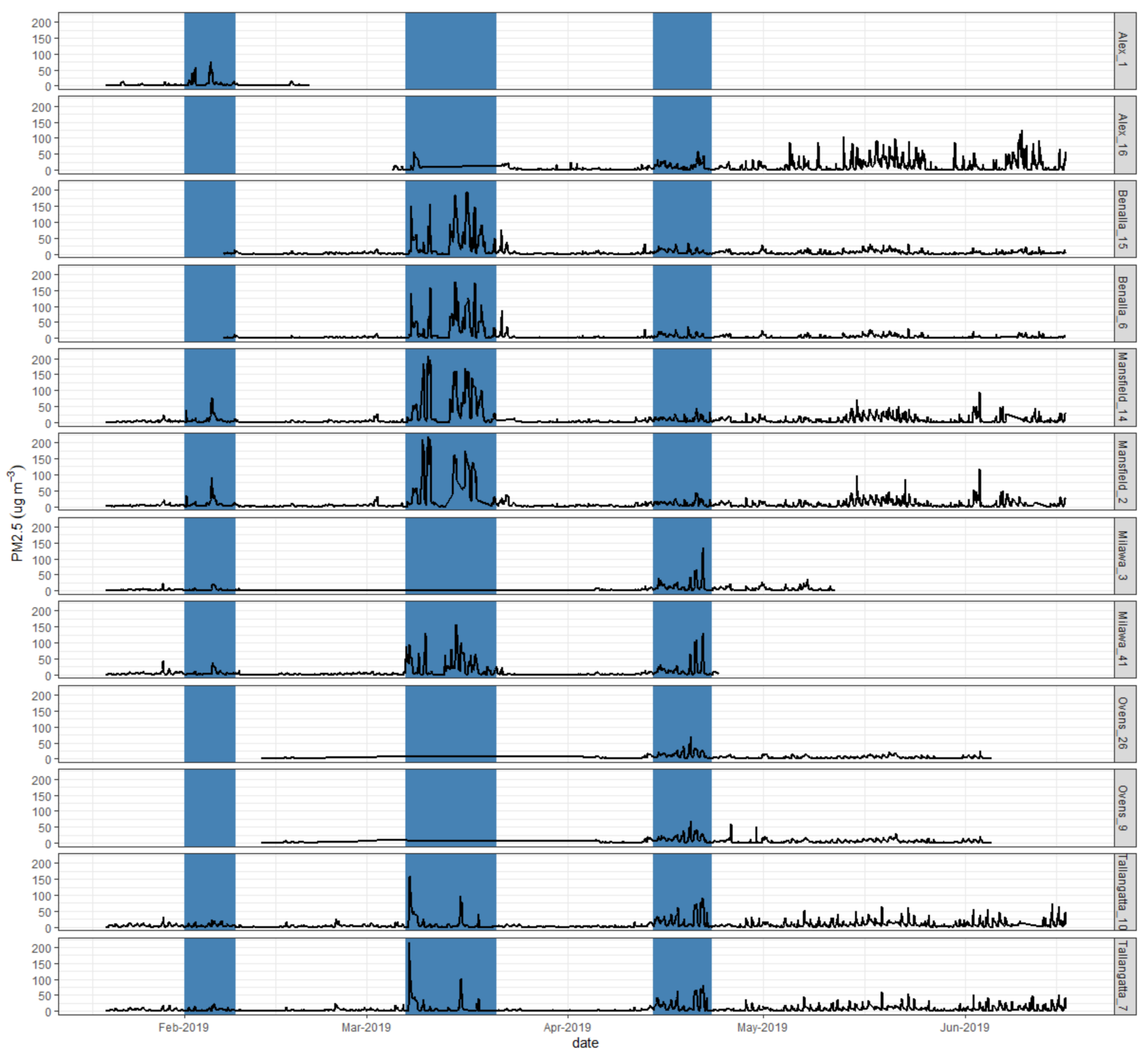

Figure 7. Time series plots of hourly $\mathrm{PM}_{2.5}$ concentrations measured at monitoring sites in NE Victoria in 2019. Shaded polygons represent the smoke plume events.

Elevated $\mathrm{PM}_{2.5}$ concentrations were further observed during winter at Alexandra, Mansfield and Tallangatta and were most likely attributed to residential wood smoke.

Results on the performance of the SMOG units during the identified smoke plume events are provided in Table 5 and in Figures S7-S11. During smoke plume events from bushfires and planned burns, the corrected $\mathrm{PM}_{2.5}$ concentrations measured with the SMOG units were in good agreement with measurements with the Fidas or E-sampler (bias $<2 \mu \mathrm{g}$ $\mathrm{m}^{-3}$, RMSE $<5 \mu \mathrm{g} \mathrm{m}^{-3}$ ). However, during winter, corrected SMOG $\mathrm{PM}_{2.5}$ concentrations were significantly higher compared to $\mathrm{PM}_{2.5}$ measurements made with the Fidas or Esampler (bias of 5.9 to $13.3 \mu \mathrm{g} \mathrm{m}^{-3}$ and NRMSE of $94-132 \%$ ). 
Table 5. Summary statistics of hourly $\mathrm{PM}_{2.5}$ concentrations measured during smoke plume events.

\begin{tabular}{|c|c|c|c|c|c|c|c|c|}
\hline Location & Date & Units & $\begin{array}{c}\text { SMOG PM }_{2.5} \\
\text { Range } \\
\left(\mu \mathrm{g} \mathrm{m}^{-3}\right)\end{array}$ & Slope & $\mathbf{r}^{2}$ & Bias (Limit) & $\begin{array}{c}\text { RMSE } \\
\left(\mu \mathrm{g} \mathrm{m}^{-3}\right)\end{array}$ & NRMSE \\
\hline \multirow{2}{*}{ Aspendale } & \multirow{2}{*}{ 26-28 June 2018} & SMOG vs. E-sampler_CF & \multirow{2}{*}{$5.0-72.4$} & $1.69 \pm 0.07$ & 0.91 & $11.5(-8.1$ to 31.1$)$ & 15.2 & 105 \\
\hline & & SMOG vs. Fidas_CF & & $2.10 \pm 0.04$ & 0.98 & $13.3(-6.3$ to 33.0$)$ & 16.6 & 132 \\
\hline \multirow{3}{*}{ Rutherglen } & \multirow{3}{*}{ 7-11 May 2018} & SMOG vs. E-sampler4_CF & \multirow{3}{*}{$0.0-39.3$} & $0.82 \pm 0.03$ & 0.88 & $-0.7(-6.4$ to 4.9$)$ & 2.96 & 50.5 \\
\hline & & SMOG vs. E-sampler5_CF & & $0.83 \pm 0.03$ & 0.87 & $-0.5(-6.3$ to 5.3$)$ & 2.99 & 53.2 \\
\hline & & SMOG vs. E-sampler_CF & & $0.90 \pm 0.02$ & 0.96 & $-1.2(-10.5$ to 8.1$)$ & 4.87 & 36.6 \\
\hline \multirow{3}{*}{ Alexandra } & \multirow{3}{*}{ 1-6 February 2019} & SMOG vs. E-sampler_OLS & \multirow{3}{*}{$0.1-75.3$} & $1.14 \pm 0.02$ & 0.96 & $1.6(-7.5$ to 10.8$)$ & 4.93 & 47.2 \\
\hline & & SMOG vs. Fidas_CF & & $1.11 \pm 0.02$ & 0.97 & $-0.25(-8.3$ to 7.8$)$ & 4.12 & 33.3 \\
\hline & & SMOG vs. Fidas_OLS & & $1.16 \pm 0.02$ & 0.97 & $0.3(-8.5$ to 9.1$)$ & 4.48 & 38.0 \\
\hline \multirow{3}{*}{ Alexandra } & \multirow{2}{*}{ 10-23 April 2019} & SMOG vs. E-sampler_CF & \multirow{2}{*}{$0.0-57.3$} & $0.97 \pm 0.03$ & 0.88 & $0.7(-7.2$ to 8.7$)$ & 4.10 & 46.8 \\
\hline & & SMOG vs. Fidas_CF & & $1.22 \pm 0.02$ & 0.97 & $1.3(-4.2$ to 6.8$)$ & 3.10 & 37.8 \\
\hline & & SMOG vs. E-sampler_CF & \multirow{4}{*}{$0.0-125$} & $1.36 \pm 0.01$ & 0.93 & $5.89(-10.5$ to 22.3$)$ & 10.2 & 89.4 \\
\hline \multirow{3}{*}{ Alexandra } & 12 May-13 June & SMOG vs. E-sampler_OLS & & $0.89 \pm 0.01$ & 0.94 & $-0.26(-15.6$ to 15.0$)$ & 7.81 & 44.4 \\
\hline & 2019 & SMOG vs. Fidas_CF & & $1.59 \pm 0.01$ & 0.99 & $5.9(-11.5$ to 23.4$)$ & 10.7 & 94.1 \\
\hline & & SMOG vs. Fidas_OLS & & $1.41 \pm 0.01$ & 0.99 & $4.5(-9.9$ to 19.0$)$ & 8.66 & 67.6 \\
\hline
\end{tabular}

Bold is used to easily identify where sensor performance was good.

Although Holder et al. [26] and Delp \& Singer [29] reported variations in linear regression parameters between smoke impacted data sets, they applied a combined smoke adjustment factor which reduced the MAE and NRMSE for all data sets and resulted in minimal error $(<20 \%)$. The data captured smoke plume events due to wildfires with likely similar particle properties.

Several research studies have shown that a combined calibration curve is suitable $[26,28,29]$ while other studies argue for a seasonal or condition-specific calibration $[20,42,69]$.

While we were able to investigate the effects of temperature and $\mathrm{RH}$ on the sensor performance other factors were not evaluated. One limitation of the study that could explain why the sensors responded differently between seasons is likely due to particle characteristics (e.g., composition and/or particle size). Mehadi et al. [33] showed an effect of EC fraction on PA sensor response, with a lower PA to reference ratio with increasing EC content. Kuula et al. [69] reported a stronger response of the PMS5003 sensor with an increased BC to PM ratio and also highlighted that accuracy of the PMS5003 sensor benefited from a residential wood smoke specific adjustment factor. As even small changes in EC/OC ratios can affect PM optical properties, the different chemical composition of residential wood smoke to smoke plumes from bushfires in summer and planned burns in autumn may be a contributing factor to the observed differences in the response of the optical instruments. The calibration curve developed in this study was determined from smoke plumes of peat fires which are likely to have a higher organic carbon content. The higher scattering efficiency of organic carbon compared to the high absorption efficiency of elemental carbon may explain the higher discrepancies between SMOG units and gravimetrically corrected reference instruments for the winter period at both Aspendale and Alexandra.

A larger scatter in the data was observed when comparing the SMOG data against the E-sampler data. This may be due to the different scattering angle between the Esampler and Plantower sensor which affects the size range within which the oscillations are more pronounced [70] and/or the use of a cyclone for PM size separation vs. optical size separation. Zamora et al. [27] have shown that the sensors performed poorly when measuring particles in the size range of $2.5-5 \mu \mathrm{m}$ while Kuula et al. [69] has shown better agreement for $\mathrm{PM}_{1}$ than for $\mathrm{PM}_{2.5}$ for wood smoke particles.

Like other educational programs using low-cost sensor technology [71], the SMOG units have proven to be a useful educational tool to teach students about particle sources and their impact on air quality. Approximately 85 Grade 5 and 6 students took part in the study with 41 SMOG units being built and deployed. The feedback from the pilot study was very positive among the students, teacher, and principal. Building the SMOG unit was the favourite activity. The students also liked that their collected data contributed to a larger scale project to further our understanding on biomass burning impacts in regional areas of Victoria. 


\section{Conclusions}

We were able to conduct a number of field-based monitoring campaigns where the SMOG units were tested over a wide range of environmental conditions (e.g., temperature and $\mathrm{RH}$ range) and $\mathrm{PM}_{2.5}$ concentration ranges. This provided us with important data on the performance of the units under different meteorological conditions and in different locations with different biomass smoke sources.

Based on the sensor performance when testing a number of units simultaneously we are confident that the SMOG units can be used to increase spatial coverage of $\mathrm{PM}_{2.5}$ monitoring, as precision between SMOG units when regularly maintained was very high.

The field-based measurements suggest that the Plantower PMS3003 dust sensor can provide relevant information about ambient $\mathrm{PM}_{2.5}$ concentrations in an airshed impacted predominantly by biomass burning, provided that an adequate adjustment factor is applied. This study suggests that a uniform adjustment factor applied to sensor data may not be appropriate across all PM sources and that a residential wood smoke adjustment factor may need to be applied to increase the accuracy of the sensor.

The study also highlighted that sensor accuracy and precision may vary depending on reference instruments used for comparison purposes.

Supplementary Materials: The following are available online at https:/ / www.mdpi.com/article/ 10.3390/s21217206/s1. Table S1. Deployment details of field-based measurements; Table S2. Data analysis parameters and equations; Table S3. Summary statistics of hourly $\mathrm{PM}_{2.5}$ concentrations measured during the rooftop tests at CSIRO Aspendale in 2018; Table S4 Summary statistics of hourly $\mathrm{PM}_{2.5}$ concentrations measured in Northeast Victoria in 2018; Table S5. Summary statistics of hourly $\mathrm{PM}_{2.5}$ concentrations measured in Northeast Victoria in 2018/2019; Figure S1. Location of the fieldbased measurement sites Figure S2. Set-up for intercomparison between SMOG units and E-samplers fitted with a $\mathrm{PM}_{2.5}$ size selective inlet; Figure S3. Boxplots for $\mathrm{PM}_{2.5}$ hourly concentrations at (a) Aspendale Autumn, (b) Aspendale winter, (c) Rutherglen (Victoria) and (d) Alexandra (Victoria). Whiskers denote the 10th and 90th percentiles; Figure S4. Bland-Altman plot of the agreement between $\mathrm{PM}_{2.5}$ concentrations measured by two SMOG units during autumn at Aspendale; Figure S5. Scatter plot and Bland-Altman plots of the agreement between $\mathrm{PM}_{2.5}$ concentrations measured by two SMOG units in Northeast Victoria; Figure S6. Linear regression analysis of optical measurements vs. gravimetric mass measurements; Figure S7. High particle event in winter at Aspendale; Figure S8. High particle event in autumn at Rutherglen; Figure S9. High particle event in summer at Alexandra; Figure S10. High particle event in autumn at Alexandra; Figure S11. High particle event in winter at Alexandra.

Author Contributions: Conceptualization, F.R.; methodology, F.R., J.C., C.R.; software, C.R.; formal analysis, F.R., J.C.P.; investigation, F.R.; data curation, F.R., C.R., J.C., J.C.P.; writing-original draft preparation, F.R., A.J.W.; writing-review and editing, F.R., A.J.W.; visualization, F.R. All authors have read and agreed to the published version of the manuscript.

Funding: This research was partially funded by the State Government of Victoria Department of Environment, Land, Water and Planning.

Institutional Review Board Statement: Not applicable.

Informed Consent Statement: Not applicable.

Data Availability Statement: Not applicable.

Acknowledgments: The authors would like to acknowledge the support by the Victorian Department of Environment, Land, Water and Planning (DELWP), the Victorian Department of Economic Development, Jobs, Transport and Resources (DEDJTR), residents in Northeast Victoria and Port Macquarie library staff. We would also like to thank the NSW Department of Planning, Industry and Environment for providing the TEOM data. We would also like to acknowledge the statistical help of D. Donaire-Gonzalez.

Conflicts of Interest: The authors declare no conflict of interest. The funders had no role in the design of the study; in the collection, analyses, or interpretation of data; in the writing of the manuscript, or in the decision to publish the results. 


\section{References}

1. Cascio, W.E. Wildland fire smoke and human health. Sci. Total Environ. 2018, 624, 586-595. [CrossRef]

2. Reid, C.E.; Brauer, M.; Johnston, F.H.; Jerrett, M.; Balmes, J.R.; Elliott, C.T. Critical Review of Health Impacts of Wildfire Smoke Exposure. Environ. Health Perspect. 2016, 124, 1334-1343. [CrossRef]

3. Doubleday, A.; Schulte, J.; Sheppard, L.; Kadlec, M.; Dhammapala, R.; Fox, J.; Isaksen, T.B. Mortality associated with wildfire smoke exposure in Washington state, 2006-2017: A case-crossover study. Environ. Health 2020, 19, 1-10. [CrossRef] [PubMed]

4. Karanasiou, A.; Alastuey, A.; Amato, F.; Renzi, M.; Stafoggia, M.; Tobias, A.; Reche, C.; Forastiere, F.; Gumy, S.; Mudu, P.; et al. Short-term health effects from outdoor exposure to biomass burning emissions: A review. Sci. Total Environ. 2021, 781, 146739. [CrossRef]

5. Arriagada, N.B.; Palmer, A.J.; Bowman, D.M.; Morgan, G.; Jalaludin, B.B.; Johnston, F.H. Unprecedented smoke-related health burden associated with the 2019-20 bushfires in eastern Australia. Med. J. Aust. 2020, 213, 282-283. [CrossRef]

6. Ford, B.; Martin, M.V.; Zelasky, S.E.; Fischer, E.V.; Anenberg, S.C.; Heald, C.L.; Pierce, J.R. Future Fire Impacts on Smoke Concentrations, Visibility, and Health in the Contiguous United States. GeoHealth 2018, 2, 229-247. [CrossRef] [PubMed]

7. Arriagada, N.B.; Horsley, J.A.; Palmer, A.J.; Morgan, G.; Tham, R.; Johnston, F.H. Association between fire smoke fine particulate matter and asthma-related outcomes: Systematic review and meta-analysis. Environ. Res. 2019, 179, 108777. [CrossRef]

8. Morgan, G.; Sheppeard, V.; Khalaj, B.; Ayyar, A.; Lincoln, D.; Jalaludin, B.; Beard, J.; Corbett, S.; Lumley, T. Effects of Bushfire Smoke on Daily Mortality and Hospital Admissions in Sydney, Australia. Epidemiology 2010, 21, 47-55. [CrossRef] [PubMed]

9. Dennekamp, M.; Abramson, M.J. The effects of bushfire smoke on respiratory health. Respirology 2011, 16, 198-209. [CrossRef]

10. Johnston, F.; Hanigan, I.; Henderson, S.; Morgan, G.; Bowman, D. Extreme air pollution events from bushfires and dust storms and their association with mortality in Sydney, Australia 1994-2007. Environ. Res. 2011, 111, 811-816. [CrossRef] [PubMed]

11. Flannigan, M.D.; Krawchuk, M.A.; De Groot, W.J.; Wotton, B.M.; Gowman, L.M. Implications of changing climate for global wildland fire. Int. J. Wildland Fire 2009, 18, 483-507. [CrossRef]

12. Johnston, F.H.; Henderson, S.B.; Chen, Y.; Randerson, J.T.; Marlier, M.; DeFries, R.S.; Kinney, P.; Bowman, D.; Brauer, M. Estimated Global Mortality Attributable to Smoke from Landscape Fires. Environ. Health Persp. 2012, 120, 695-701. [CrossRef]

13. Turetsky, M.R.; Kane, E.S.; Harden, J.W.; Ottmar, R.D.; Manies, K.L.; Hoy, E.; Kasischke, E.S. Recent acceleration of biomass burning and carbon losses in Alaskan forests and peatlands. Nat. Geosci. 2010, 4, 27-31. [CrossRef]

14. Westerling, A.L.; Hidalgo, H.G.; Cayan, D.R.; Swetnam, T.W. Warming and earlier spring increase western US forest wildfire activity. Science 2006, 313, 940-943. [CrossRef]

15. Gupta, P.; Doraiswamy, P.; Levy, R.; Pikelnaya, O.; Maibach, J.; Feenstra, B.; Polidori, A.; Kiros, F.; Mills, K.C. Impact of California Fires on Local and Regional Air Quality: The Role of a Low-Cost Sensor Network and Satellite Observations. GeoHealth 2018, 2, 172-181. [CrossRef]

16. Mallia, D.V.; Kochanski, A.K.; Kelly, K.E.; Whitaker, R.; Xing, W.; Mitchell, L.E.; Jacques, A.; Farguell, A.; Mandel, J.; Gaillardon, P.E.; et al. Evaluating Wildfire Smoke Transport Within a Coupled Fire-Atmosphere Model Using a High-Density Observation Network for an Episodic Smoke Event Along Utah's Wasatch Front. J. Geophys. Res.-Atmos. 2020, 125, e2020JD032712. [CrossRef]

17. Lin, C.; Labzovskii, L.D.; Mak, H.W.L.; Fung, J.C.; Lau, A.K.; Kenea, S.T.; Bilal, M.; Hey, J.D.V.; Lu, X.; Ma, J. Observation of PM2.5 using a combination of satellite remote sensing and low-cost sensor network in Siberian urban areas with limited reference monitoring. Atmos. Environ. 2020, 227, 117410. [CrossRef]

18. Lu, X.; Zhang, X.; Li, F.; Cochrane, M.; Ciren, P. Detection of Fire Smoke Plumes Based on Aerosol Scattering Using VIIRS Data over Global Fire-Prone Regions. Remote Sens. 2021, 13, 196. [CrossRef]

19. Reisen, F.; Meyer, C.M.; McCaw, L.; Powell, J.C.; Tolhurst, K.; Keywood, M.D.; Gras, J.L. Impact of smoke from biomass burning on air quality in rural communities in southern Australia. Atmos. Environ. 2011, 45, 3944-3953. [CrossRef]

20. Zusman, M.; Schumacher, C.S.; Gassett, A.J.; Spalt, E.W.; Austin, E.; Larson, T.V.; Carvlin, G.; Seto, E.; Kaufman, J.D.; Sheppard, L. Calibration of low-cost particulate matter sensors: Model development for a multi-city epidemiological study. Environ. Int. 2020, 134, 105329. [CrossRef] [PubMed]

21. Borrego, C.; Ginja, J.; Coutinho, M.; Ribeiro, C.; Karatzas, K.; Sioumis, T.; Katsifarakis, N.; Konstantinidis, K.; De Vito, S.; Esposito, E.; et al. Assessment of air quality microsensors versus reference methods: The EuNetAir Joint Exercise-Part II. Atmos. Environ. 2018, 193, 127-142. [CrossRef]

22. Feinberg, S.; Williams, R.; Hagler, G.S.W.; Rickard, J.; Brown, R.; Garver, D.; Harshfield, G.; Stauffer, P.; Mattson, E.; Judge, R.; et al. Long-term evaluation of air sensor technology under ambient conditions in Denver, Colorado. Atmos. Meas. Tech. 2018, 11, 4605-4615. [CrossRef]

23. Jayaratne, R.; Liu, X.; Thai, P.; Dunbabin, M.; Morawska, L. The influence of humidity on the performance of a low-cost air particle mass sensor and the effect of atmospheric fog. Atmos. Meas. Tech. 2018, 11, 4883-4890. [CrossRef]

24. Ardon-Dryer, K.; Dryer, Y.; Williams, J.N.; Moghimi, N. Measurements of PM2.5 with PurpleAir under atmospheric conditions. Atmos. Meas. Tech. 2020, 13, 5441-5458. [CrossRef]

25. Bulot, F.M.J.; Johnston, S.J.; Basford, P.J.; Easton, N.H.C.; Apetroaie-Cristea, M.; Foster, G.L.; Morris, A.K.R.; Cox, S.J.; Loxham, M. Long-term field comparison of multiple low-cost particulate matter sensors in an outdoor urban environment. Sci. Rep. 2019, 9, $1-13$.

26. Holder, A.L.; Mebust, A.K.; Maghran, L.A.; McGown, M.R.; Stewart, K.E.; Vallano, D.M.; Elleman, R.A.; Baker, K.R. Field Evaluation of Low-Cost Particulate Matter Sensors for Measuring Wildfire Smoke. Sensors 2020, 20, 4796. [CrossRef] 
27. Zamora, M.L.; Xiong, F.; Gentner, D.R.; Kerkez, B.; Kohrman-Glaser, J.; Koehler, K. Field and Laboratory Evaluations of the Low-Cost Plantower Particulate Matter Sensor. Environ. Sci. Technol. 2018, 53, 838-849. [CrossRef]

28. Barkjohn, K.K.; Gantt, B.; Clements, A.L. Development and application of a United States-wide correction for PM2.5 data collected with the PurpleAir sensor. Atmos. Meas. Tech. 2021, 14, 4617-4637. [CrossRef]

29. Delp, W.W.; Singer, B.C. Wildfire Smoke Adjustment Factors for Low-Cost and Professional PM(2.5)Monitors with Optical Sensors. Sensors 2020, 20, 3683. [CrossRef]

30. Robinson, D.L. Accurate, Low Cost PM(2.5)Measurements Demonstrate the Large Spatial Variation in Wood Smoke Pollution in Regional Australia and Improve Modeling and Estimates of Health Costs. Atmosphere 2020, 11, 856.

31. Bulot, F.M.J.; Russell, H.S.; Rezaei, M.; Johnson, M.S.; Ossont, S.J.J.; Morris, A.K.R.; Basford, P.J.; Easton, N.H.C.; Foster, G.L.; Loxham, M.; et al. Laboratory Comparison of Low-Cost Particulate Matter Sensors to Measure Transient Events of Pollution. Sensors 2020, 20, 2219. [CrossRef] [PubMed]

32. Kuula, J.; Mäkelä, T.; Aurela, M.; Teinilä, K.; Varjonen, S.; González, Ó.; Timonen, H. Laboratory evaluation of particle-size selectivity of optical low-cost particulate matter sensors. Atmos. Meas. Tech. 2020, 13, 2413-2423. [CrossRef]

33. Mehadi, A.; Moosmüller, H.; Campbell, D.E.; Ham, W.; Schweizer, D.; Tarnay, L.; Hunter, J. Laboratory and field evaluation of real-time and near real-time PM2.5 smoke monitors. J. Air Waste Manag. Assoc. 2020, 70, 158-179. [CrossRef] [PubMed]

34. Tryner, J.; L'Orange, C.; Mehaffy, J.; Miller-Lionberg, D.; Hofstetter, J.C.; Wilson, A.; Volckens, J. Laboratory evaluation of low-cost PurpleAir PM monitors and in-field correction using co-located portable filter samplers. Atmos. Environ. 2020, $220,117067$. [CrossRef]

35. Tryner, J.; Mehaffy, J.; Miller-Lionberg, D.; Volckens, J. Effects of aerosol type and simulated aging on performance of low-cost PM sensors. J. Aerosol Sci. 2020, 150, 105654. [CrossRef]

36. Wang, W.-C.V.; Lung, S.-C.C.; Liu, C.H.; Shui, C.-K. Laboratory Evaluations of Correction Equations with Multiple Choices for Seed Low-Cost Particle Sensing Devices in Sensor Networks. Sensors 2020, 20, 3661. [CrossRef] [PubMed]

37. Zou, Y.Y.; Clark, J.D.; May, A.A. Laboratory evaluation of the effects of particle size and composition on the performance of integrated devices containing Plantower particle sensors. Aerosol. Sci. Tech. 2021, 55, 848-858.

38. Zou, Y.Y.; Clark, J.D.; May, A.A. A systematic investigation on the effects of temperature and relative humidity on the performance of eight low-cost particle sensors and devices. J. Aerosol. Sci. 2021, 152, 105715. [CrossRef]

39. Jayaratne, R.; Liu, X.; Ahn, K.-H.; Asumadu-Sakyi, A.; Fisher, G.; Gao, J.; Mabon, A.; Mazaheri, M.; Mullins, B.; Nyarku, M.; et al. Low-cost PM2.5 Sensors: An Assessment of Their Suitability for Various Applications. Aerosol Air Qual. Res. 2020, 20, 520-532. [CrossRef]

40. Liu, X.; Jayaratne, R.; Thai, P.; Kuhn, T.; Zing, I.; Christensen, B.; Lamont, R.; Dunbabin, M.; Zhu, S.; Gao, J.; et al. Low-cost sensors as an alternative for long-term air quality monitoring. Environ. Res. 2020, 185, 109438. [CrossRef]

41. Lung, S.-C.C.; Wang, W.-C.V.; Wen, T.-Y.J.; Liu, C.-H.; Hu, S.-C. A versatile low-cost sensing device for assessing PM2.5 spatiotemporal variation and quantifying source contribution. Sci. Total Environ. 2020, 716, 137145. [CrossRef]

42. Sayahi, T.; Butterfield, A.; Kelly, K. Long-term field evaluation of the Plantower PMS low-cost particulate matter sensors. Environ. Pollut. 2019, 245, 932-940. [CrossRef]

43. Stampfer, O.; Austin, E.; Ganuelas, T.; Fiander, T.; Seto, E.; Karr, C.J. Use of low-cost PM monitors and a multi-wavelength aethalometer to characterize PM2.5 in the Yakama Nation reservation. Atmos. Environ. 2020, 224, 117292. [CrossRef]

44. Peltier, R.E.; Castell, N.; Clements, A.L.; Dye, T.; Hüglin, C.; Kroll, J.H.; Lung, S.C.C.; Ning, Z.; Parsons, M.; Penza, M.; et al. An Update on Low-cost Sensors for the Measurement of Atmospheric Composition; WMO: Geneva, Switzerland, 2021.

45. Kelly, K.; Whitaker, J.; Petty, A.; Widmer, C.; Dybwad, A.; Sleeth, D.; Martin, R.; Butterfield, A. Ambient and laboratory evaluation of a low-cost particulate matter sensor. Environ. Pollut. 2017, 221, 491-500. [CrossRef] [PubMed]

46. Zheng, T.; Bergin, M.H.; Johnson, K.K.; Tripathi, S.N.; Shirodkar, S.; Landis, M.S.; Sutaria, R.; Carlson, D.E. Field evaluation of low-cost particulate matter sensors in high- and low-concentration environments. Atmos. Meas. Tech. 2018, 11, 4823-4846. [CrossRef]

47. Allen, G.; Sioutas, C.; Koutrakis, P.; Reiss, R.; Lurmann, F.W.; Roberts, P.T. Evaluation of the TEOM(R) method for measurement of ambient particulate mass in urban areas. J. Air Waste Manag. 1997, 47, 682-689. [CrossRef] [PubMed]

48. Wheeler, A.; Allen, R.; Lawrence, K.; Roulston, C.; Powell, J.; Williamson, G.; Jones, P.; Reisen, F.; Morgan, G.; Johnston, F. Can Public Spaces Effectively Be Used as Cleaner Indoor Air Shelters during Extreme Smoke Events? Int. J. Environ. Res. Public Health 2021, 18, 4085. [CrossRef]

49. Wallace, L.A.; Wheeler, A.J.; Kearney, J.; Van Ryswyk, K.; You, H.Y.; Kulka, R.H.; Rasmussen, P.E.; Brook, J.R.; Xu, X.H. Validation of continuous particle monitors for personal, indoor, and outdoor exposures. J. Expo. Sci. Environ. Epidemiol. 2010, $21,49-64$. [CrossRef] [PubMed]

50. Legendre, P. Lmodel2: Model II Regression. R Package Version 1.7-3. 2018. Available online: https://CRAN.R-project.org/ package $=$ lmodel2 (accessed on 5 October 2021).

51. Lin, L.I.-K. A Concordance Correlation Coefficient to Evaluate Reproducibility. Biometrics 1989, 45, 255. [CrossRef]

52. Lin, L. A note on the concordance correlation coefficient. Biometrics 2000, 56, 324-325.

53. Stevenson, M.; Sergeant, E. Epir: Tools for the Analysis of Epidemiological Data. R Package Version 2.0.26. 2021. Available online: https:/ /CRAN.R-project.org/package=epiR (accessed on 5 October 2021). 
54. R Core Team. R: A Language and Environment for Statistical Computing; R Foundation for Statistical Computing: Vienna, Austria, 2021; Available online: https:/ / www.R-project.org/ (accessed on 5 October 2021).

55. Bland, J.M.; Altman, D.G. Statistical methods for assessing agreement between two methods of clinical measurement. Lancet 1986, 327, 307-310. [CrossRef]

56. Kosmopoulos, G.; Salamalikis, V.; Pandis, S.; Yannopoulos, P.; Bloutsos, A.; Kazantzidis, A. Low-cost sensors for measuring airborne particulate matter: Field evaluation and calibration at a South-Eastern European site. Sci. Total Environ. 2020, 748, 141396. [CrossRef] [PubMed]

57. Barkjohn, K.J.; Bergin, M.H.; Norris, C.; Schauer, J.J.; Zhang, Y.; Black, M.; Hu, M.; Zhang, J. Using Low-cost sensors to Quantify the Effects of Air Filtration on Indoor and Personal Exposure Relevant PM2.5 Concentrations in Beijing, China. Aerosol Air Qual. Res. 2020, 20, 297-313. [CrossRef]

58. Wallace, L.; Bi, J.; Ott, W.R.; Sarnat, J.; Liu, Y. Calibration of low-cost PurpleAir outdoor monitors using an improved method of calculating PM. Atmos. Environ. 2021, 256, 118432. [CrossRef]

59. Croghan, W.; Egeghy, P.P. Methods of Dealing with Values below the Limit of Detection Using SAS. In Proceedings of the Southern SAS User Group, St. Petersburg, FL, USA, 22-24 September 2003.

60. U.S. Environmental Protection Agency. Data Quality Assessment: Statistical Methods for Practitioners; Office of Environmental Information: Washington, DC, USA, 2006.

61. Chung, A.; Chang, D.P.; Kleeman, M.J.; Perry, K.D.; Cahill, T.A.; Dutcher, D.; McDougall, E.M.; Stroud, K. Comparison of Real-Time Instruments Used To Monitor Airborne Particulate Matter. J. Air Waste Manag. Assoc. 2001, 51, 109-120. [CrossRef]

62. Heal, M.R.; Beverland, I.J.; McCabe, M.; Hepburn, W.; Agius, R.M. Intercomparison of five PM10 monitoring devices and the implications for exposure measurement in epidemiological research. J. Environ. Monit. 2000, 2, 455-461. [CrossRef] [PubMed]

63. Kingham, S.; Durand, M.; Aberkane, T.; Harrison, J.; Wilson, J.G.; Epton, M. Winter comparison of TEOM, MiniVol and DustTrak PM(10) monitors in a woodsmoke environment. Atmos. Environ. 2006, 40, 338-347. [CrossRef]

64. Singer, B.C.; Delp, W.W. Response of consumer and research grade indoor air quality monitors to residential sources of fine particles. Indoor Air 2018, 28, 624-639. [CrossRef]

65. Carrico, C.M.; Prenni, A.J.; Kreidenweis, S.M.; Levin, E.J.T.; McCluskey, C.S.; DeMott, P.J.; McMeeking, G.R.; Nakao, S.; Stockwell, C.; Yokelson, R.J. Rapidly evolving ultrafine and fine mode biomass smoke physical properties: Comparing laboratory and field results. J. Geophys. Res. Atmos. 2016, 121, 5750-5768. [CrossRef]

66. Duvall, R.M.; Clements, A.L.; Hagler, G.; Kamal, A.; Kilaru, V.; Goodman, L.; Frederick, S.; Barkjohn, K.; VonWald, I.; Greene, D.; et al. Performance Testing Protocols, Metrics, and Target Values for Fine Particulate Matter Air Sensors. Use in Ambient, Outdoor, Fixed Site, Non-Regulatory Supplemental and Informational Monitoring Applications; Office of Research and Development and Center for Environmental Measurement and Modelling, Ed.; U.S. Environmental Protection Agency: Washington, DC, USA, 2021.

67. Rai, A.; Kumar, P.; Pilla, F.; Skouloudis, A.N.; DI Sabatino, S.; Ratti, C.; Yasar, A.-U.-H.; Rickerby, D. End-user perspective of low-cost sensors for outdoor air pollution monitoring. Sci. Total Environ. 2017, 607-608, 691-705. [CrossRef] [PubMed]

68. South Coast Air Quality Management District. Field evaluation Laser Egg PM Sensor. 2017. Available online: http://www.aqmd. gov / docs / default-source/aq-spec/ field-evaluations/laser-egg---field-evaluation.pdf (accessed on 5 October 2021).

69. Kuula, J.; Friman, M.; Helin, A.; Niemi, J.V.; Aurela, M.; Timonen, H.; Saarikoski, S. Utilization of scattering and absorption-based particulate matter sensors in the environment impacted by residential wood combustion. J. Aerosol Sci. 2020, 150, 105671. [CrossRef]

70. Alfano, B.; Barretta, L.; Del Giudice, A.; De Vito, S.; Di Francia, G.; Esposito, E.; Formisano, F.; Massera, E.; Miglietta, M.L.; Polichetti, T. A Review of Low-Cost Particulate Matter Sensors from the Developers' Perspectives. Sensors 2020, $20,6819$. [CrossRef] [PubMed]

71. Ellenburg, J.A.; Williford, C.J.; Rodriguez, S.L.; Andersen, P.C.; Turnipseed, A.A.; Ennis, C.A.; Basman, K.A.; Hatz, J.M.; Prince, J.C.; Meyers, D.H.; et al. Global Ozone (GO3) Project and AQTreks: Use of evolving technologies by students and citizen scientists to monitor air pollutants. Atmos. Environ. X 2019, 4, 100048. [CrossRef] 